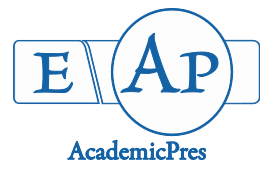

\title{
Veterinary Medical Students' Perceptions, Attitude and Knowledge about Antibiotic Resistance and Stewardship: How Prepared Are Our Future Prescribers?
}

\section{Madubuike Umunna ANYANWU ${ }^{1 *}$, Onyinye Josephine OKORIE-KANU², Chidiebere Ohazuruike ANYAOHA², Oluwatosin Ajoke KOLADE ${ }^{3}$}

\author{
${ }^{1}$ University of Nigeria, Microbiology Unit, Department of Veterinary Pathology and Microbiology, \\ Nsukka, Nigeria; madubuike.anyanwu@unn.edu.ng ('corresponding author) \\ ${ }^{2}$ University of Nigeria, Department of Public Health and Preventive Medicine, \\ Nsukka,Nigeria; chidi.anyaoha@unn.edu.ng; onyinye.okoro@unn.edu.ng \\ ${ }^{3}$ University of Nigeria, Veterinary Teaching Hospital, Nsukka, Nigeria; oluwatosin.kolade@unn.edu.ng
}

\begin{abstract}
A cross sectional, multicentre survey utilizing a questionnaire was used to assess $6^{\text {th }}$ - (final-) year veterinary medical students' perceptions, attitude and knowledge about antibiotic resistance (ABR) and stewardship (ABS) in 5 convenientlyselected veterinary schools in Nigeria. Data obtained were analyzed by Fischer's exact and $\chi^{2}$ tests at a significance level of $P<$ 0.05. Out of 175 final-year veterinary students, 95 (54.3\% i.e., response rate) completed the survey. Of the $95,17 \%$ have heard about $\mathrm{ABS}$ and $7 \%$ knew the meaning of ABS. Less than 10\% knew the core principles and goals of $\mathrm{ABS}$ and less than $20 \%$ of the respondents knew the ideal members of an ABS team. All the respondents rightly knew that no antibiotic stewardship programme (ASP) exist in veterinary hospitals in Nigeria, nearly all of them (97\%) reported that antibiograms are rarely used during antibiotic $(\mathrm{AB})$ prescription in their institutional veterinary teaching hospital (VTH) and about two-third (65\%) believed that $A B s$ are overused in most veterinary hospitals in Nigeria. Most of the respondents believed that $A B R$ is of greater concern at national level than in their institutional VTHs and majority of them (92\%) believed that ABR is a global problem $(P=0.009)$. Minority of the respondents knew that inadequate personal hygiene, use of substandard ABs, prescription of $\mathrm{ABs}$ by non-veterinarians/professionals, poor infection control practices, treating self-limiting infections with ABs, suboptimal and incomplete $\mathrm{AB}$ doses $(P=0.017)$, are factors that promote $\mathrm{ABR}$. Minority of the respondents knew that education on $\mathrm{AB}$ therapy (44\%), development of antibiotic usage policies (35\%), reduction of $\mathrm{AB}$ use (14\%), establishment of national $\mathrm{AB}$ resistance surveillance (28\%) and development of institutional guidelines for $\mathrm{AB}$ use (29\%), are critical interventions to curb $A B R$. Only $17 \%$ of the respondents felt that their education on $A B R$ is adequate for their veterinary career. Most of the respondents believed that strong knowledge of $\mathrm{ABs}$ is important for their future veterinary career and would like more education about $A B R$ and $A B S$. Overall mean correct score of $29 \%$ on clinical knowledge vignettes with similar scores across the schools in all the areas, was recorded. This survey has shown that Nigerian veterinary students' perception and knowledge about $A B R$ and $A B S$ are poor and therefore creates doubt about their preparedness to practice ABS. There is urgent need for improved ABS education in Nigerian veterinary schools.
\end{abstract}

Keywords: antibiotic resistance; antibiotic stewardship; education; veterinary medical students

\section{Introduction}

Antibiotic resistance $(\mathrm{ABR})$ occupies the centre stage in global public health agenda because it is a "tragedy of the commons" affecting both developed and developing nations (O’Neil, 2014; Lanza et al., 2017). The threat posed by $\mathrm{ABR}$ has been equated to climatic change and this is of grave concern globally (Castro-Sanchezet al., 2016; Friedman et al., 2016; Moran, 2017). It is known that ABR could potentially exert catastrophic economic and health impact which on a global scale is enormous and dreadful (Zaidi et al., 2004; Cisnerosetal., 2014; O'Neil, 2014; Prestinaci et al., 2015; Fitchet and Antun, 2016). 
Amongst the numerous contributions to $A B R$, inappropriate use of antibiotics (ABs), especially wrong prescribing behavior by healthcare professionals, including veterinarians, have been identified as a major factor that promote ABR(Cotta etal.,2014; Wasserman et al., 2017). Lack of knowledge required for appropriate use of $A B$ and scarce training offered to healthcare professionals, have been identified as the major cause of wrong use of $\mathrm{AB}$ by heal thcare/veterinary practitioners (Cisneros et al., 2014). It is known that $\mathrm{AB}$ is prescribed by virtually all clinicians/veterinarians, including allied healthcare professionals, regardless of training or knowledge (Abbo $e t$ al., 2013; Wasserman et al., 2017).

Veterinarysettings are reservoirs of zoonotic multidrugresistant organisms, particularly in developing countries, includingNigeria, owing to inappropriate use of $\mathrm{ABs}$ (Van Boeckel et al.,2015; Moran, 2017). Therefore, veterinarians are expected to be in the frontline of the fight against $A B R$ (Castro-Sanchez et al., 2016; Brink, et al., 2017; Moran, 2017; Dyar etal., 2018). Optimization of AM prescribing is the best way to checkmate escalating ABR worldwide and to preserve $\mathrm{AB}$ for future generations (Broom et al., 2016; Moran, 2017). Interventions that strengthen the concept of 'One-Health' at the human-animal interface such as antibioticstewardship (ABS), have been established the best strategy to contain ABR (Cisneros et al., 2014; Bowater, 2015; O'Donnel and Guarrascio, 2016; Wasserman et al. 2017). Education (especially of the healthcare workers and the public) on $A B$ therapy and $A B R$ is considered one of the most important interventions/strategy of ABS (Wasserman et al., 2017; O'Donnel and Guarrascio, 2017; MacDougall et al., 2017). The World Health Organization (WHO) identified education of healthcare workers and health profession students on rational $A B$ prescribing and $A B S$ as an integral partofall $\mathrm{ABR}$ containment activities (Vickers, 2011; WHO, 2012; Abbo et al., 201; Hoque et al., 2016). It has been observed that ABS efforts in most parts of the world focused more on understanding the perceptions of practicing physicians/veterinarians and modifying their behaviors, with far less attention beingpaid to the education of medical and veterinary medical students (Abbo et al., 2013; Luther et al., 2013; MacDougall et al., 2017). It is a well-establ ished fact that for ABR to be contained, the next generation of healthcare professionals, particularly the physicians and veterinarians who are the major prescribers and/or dispensers of $A B s$, must be better prepared to use AB more judiciously (Abbo et al., 2013; Fairles, 2013; Schwartz, 2016; O’Donnel and Guarascio, 2017). Thus, education of veterinary medical undergraduate students on $\mathrm{ABS}$ is critical for the control of $\mathrm{ABR}$ because these future veterinarians are to be in the frontline (as professionals and educators of other allied healthcare professionals, the public and their clients/patients) in infection control, development, establishment and implementation of ASPs (Delit et al., 2007; Wasserman et al., 2017; O'Donnel and Guarascio, 2017). A veterinarian with insufficient knowledge about $\mathrm{ABs}, \mathrm{ABR}$ and $\mathrm{ABS}$ would neitherbe able to practice $A B S$ norlead others in stewardship programmes (Brink et al., 2017). Moreover, it is difficult for veterinarians to change habits that are untoward $\mathrm{ABS}$ once they are formed (Weier et al., 2017). Inadequate preparation at undergraduate level in veterinary schools may result in practices that are un toward $\mathrm{ABS}$, particularly inappropriate $\mathrm{AB}$ use/prescribing (Wasserman et al., 2017); therefore, there is need to equip veterinary students with adequate ABS knowledge and skills prior to their entry into the veterinary workforce (MacDougal et al., 2017; Wasserman et al., 2017; Weier et al., 2017).

Assessing veterinary students' perception and level of knowledge about $A B R$ and $A B S$ and their preparedness to practice ABS is crucial for identifying gaps in knowledge; such information could be useful for policy makers in developing adequate ABS educational programmes for veterinarians, improving curricula in veterinary schools and development of effective ASPs in veterinary hospitals (Cotta etal., 2014; Gharbi etal., 2016; Hoque et al., 2016). Several studies have assessed medical/allied healthcare profession students' perceptionsand knowledge about $A B$, $A B R$ and/or $A B S$ and their perceptions about how prepared they are to practice ABS (Minen et al., 2010; Pulcini et al., 2011; Abbo et al., 2013; Afzal Khan et al., 2013; Justo et al., 2013, Thriemer et al., 2013; Dyar et al., 2014; Harakeh etal., 2015; Taraoetal., 2015; Burger et al., 2016; Ferdoush etal., 2016; Haque et al., 2016; Hoque et al., 2016; Padmanabha et al.,2016; Yang et al., 2016; Weier et al., 2017; Dyar et al., 2018; Wasserman et al., 2017). These studies reported significant differences among the students in terms of perceptions and knowledge about ABS and ABR. Studies eval uating veterinary medical students' perceptions and knowledge about $\mathrm{ABR}$ and $\mathrm{ABS}$ and their preparedness to practice $A B S$, are rare in theliterature. The onlystudy which assessed veterinary students' perception and knowledge about ABR and ABS is that of Dyar et al. (2018) in the United Kingdom(UK). Therehavebeen calls (Wesse etal.,2015; Brink etal., 2017; Dyar et al., 2018) for studies evaluating veterinary students' perceptions and knowledge about $\mathrm{ABR}$ and $\mathrm{ABS}$.

In Nigerian veterinarymedical schools, courses on $A B R$ are taught in the $3^{\text {rd }}$ and $4^{\text {th }}$ years in Microbiology and Pharmacology, and students are further exposed to $A B$ sensitivity testing and prescription in the $6^{\text {th }}$ (final) year during clinical postings/rotations in their respective institutional veterinary teaching hospitals (VTHs) (Anyanwu and Kolade, 2017). No study has evaluated Nigerian veterinary medical students' perceptions, attitude and knowledge about ABR and ABS. Likewise there are no data on the perception of Nigerian veterinary students about their preparedness to practice ABS. This study was, therefore, undertaken to assess final-year veterinary medical students' perceptions and knowledge about ABR and ABS.

\section{Materials and Methods}

\section{Study design, site and population}

This cross-sectional, multicentre descriptive survey was carried out between June and August, 2017 in 5 (out of 10 registered) Universities in Nigeria offering Veterinary Medicine (VM): the University of Nigeria, Nsukka in Enugu State southeastern region, the Michael Okpara Federal University of Agriculture, Umudike in Abia State southeastern region, the Ahmadu Bello University, Zariain 
158

Kaduna State northwest region, the Federal University of Agriculture, Markurdi in northcentral region and the University of Abujain the Federal Capital Territory. The University of Nigeria, Nsukka served as the coordinating site. The participating schools were selected by convenience sampling. The total number of registered final-year veterinary medical students (VMS) in these five participating schools as at the period of the study was 175 (Table 1). The target population comprised of all registered final-yearVMS in the various schools. Only those who were willing to participate in the survey and provided written informed consent were included in the study. The $6^{\text {th }}$-year was selected purposefully for this survey because it is thelast (final) year of undergraduate studies in VM schools in Nigeria and a good estimation of the knowledge of veterinary studentsabout $A B R$ and $A B S$ could be obtained at this level since these students have completed their preclinical and clinical years, including rotations in their respective institutional VTHs.

\section{Ethical approval}

Ethical approval was not necessary for this study; however, permission to conduct the study was obtained from the University of Nigeria Research Ethics Committee. Permission to conduct the studyin each of the participating sites was obtained from the lecturer who served as the Head/Coordinatorof the final-year class. Informed consent of all participants involved in the study was obtained and confidentiality and anonymity of the data obtained was ensured.

\section{Data collection}

Information about students' demographics, knowledge/perceptions of principles, goals and development strategies of $\mathrm{ABS}, \mathrm{ABR}$ and $\mathrm{AB}$ use/prescribing, resources used for $A B$ education and clinical knowledge vignettes, was collected using a selfadministered structured questionnaire. The questionnaire was developed after thorough review and modification (to adapt for veterinary students) of comparable studies (Abbo et al., 2013; Burger et al., 2016; Yang et al., 2016; Wasserman et al.,2017) and validated by a pilot study on 15 fresh VM graduates from the 5 veterinary schools. Knowledge was assessed using 11 validated clinical vignettes (Abbo et al., 2013; Yang et al., 2016). The surveys were administered to final-year VM students during whole class lecturesat the participatingveterinary schools. Thestudents were instructed to abstain from using resources or consulting peersin filling the survey (Thriemer et al., 2013; Justo etal., 2014; Wasserman et al., 2017). They were also asked to fill the questionnaires on-site within 4 hours to ensure that consultation of resources and peers are precluded (Thriemer et al.,2013). No incentives were given to the participants. Participation was voluntary and responses were anonymous.

\section{Data analysis}

The participating veterinary medical schools were deidentified as "A", "B", "C", "D" and "E" in order to conduct blinded data analysis. Answers to questions that used a 5point Likert scale were merged into two dichotonomous categories (strongly agree/agree and strongly disagree/disagree/neutral, often/occasionally/sometimes and rarely/never, very good/good and poor/very poor/neutral) (Abbo et al., 2013; Justo et al., 2014; Yang et al. 2016). Data were entered into Microsoft Excel sheet version 15.0 and exported to SPSS version 15.0 for analysis. Frequencies and percentages of all variables were calculated. Non parametric testswere used to assess for the presence of any significant difference among the students' response from the 5 survey sites. The Fischer's exact and $\chi^{2}$ tests were used to compare the parameters as appropriate and statistical significance was set at $P<0.05$. An overall knowledge score was evaluated by calculating the total percentages (each counts one point) of correct answers for the vignette-based questions (Abooet al., 2013; Yang et al., 2016).

\section{Results}

\section{Response rate}

Ninety five final-year VMS out of a total of 175 registered students in the 5 veterinary schools completed the survey for an overall response rate of 54.3\% (range across schools,31.7\%-100\%). Response rate by schools are shown in Table 1.

\section{Student demographics}

Overall,65.3\% (62/95) of the respondents were males while $34.7 \%$ (33/95) were females. More than two-third $(70.5 \%, 67 / 95)$ of the respondentswere between the ages of 20 and 25 years, $26.3 \%(25 / 95)$ were between 26 and 30 years while $3.2 \%(3 / 95)$ were 30 years and above.

\section{Background knowledge and perceptions of antibiotic stewardship \\ Respondents' background knowledge and perceptions} about ABS are summarized in Table 2. Overall, a low proportion $(17 \%)$ of the respondents agreed that they have heard of $A B S$, with $8 \%, 2 \%, 3 \%, 7 \%$ and $1 \%$ of these having heard or learnt about ABS from lecturer(s), peers, senior

Table 1 . Response rate by school

\begin{tabular}{|c|c|c|c|}
\hline \multirow{2}{*}{ University } & \multirow{2}{*}{$\begin{array}{c}\text { Number of final-year Veterinary } \\
\text { Medicine students }\end{array}$} & \multicolumn{2}{|c|}{ Response rate } \\
\hline & & Number (n) & Percentage \\
\hline $\mathrm{A}$ & 45 & 25 & 55.6 \\
\hline B & 63 & 20 & 31.7 \\
\hline $\mathrm{C}$ & 32 & 19 & 59.4 \\
\hline $\mathrm{D}$ & 22 & 18 & 81.8 \\
\hline $\mathrm{E}$ & 13 & 13 & 100 \\
\hline All & 175 & 95 & 54.3 \\
\hline
\end{tabular}


Table 2. Veterinary medical students' background knowledge and perceptions of antibiotic stewardship

\begin{tabular}{|c|c|c|c|c|c|c|c|}
\hline \multirow{3}{*}{ Background knowledge } & \multicolumn{6}{|c|}{ Percentage (rounded) of students per university who strongly agree/agree } & \multirow{3}{*}{$P$ value } \\
\hline & \multicolumn{6}{|c|}{ School } & \\
\hline & $\begin{array}{c}\text { All } \\
(\mathrm{n}=95)\end{array}$ & $\begin{array}{c}A \\
(n=25)\end{array}$ & $\begin{array}{c}\text { B } \\
(n=20)\end{array}$ & $\begin{array}{c}\mathrm{C} \\
(\mathrm{n}=19)\end{array}$ & $\begin{array}{c}\mathrm{D} \\
(\mathrm{n}=18)\end{array}$ & $\begin{array}{c}E \\
(n=13)\end{array}$ & \\
\hline $\begin{array}{l}\text { I am familiar with the term or have heard } \\
\text { about antibiotic stewardship }\end{array}$ & $17 \%$ & $24 \%$ & $20 \%$ & $16 \%$ & $6 \%$ & $15 \%$ & $0.621^{\mathrm{a}}$ \\
\hline $\begin{array}{l}\text { I know the meaning of antibiotic } \\
\text { stewardship }\end{array}$ & $7 \%$ & $8 \%$ & $15 \%$ & $5 \%$ & $0 \%$ & $8 \%$ & $0.567^{\mathrm{a}}$ \\
\hline \multicolumn{8}{|c|}{ Source/Means from which antibiotic stewardship was heard/learnt } \\
\hline Lecturer & $8 \%$ & $20 \%$ & $0 \%$ & $5 \%$ & $0 \%$ & $15 \%$ & $0.050^{\mathrm{a}}$ \\
\hline Peers (other students) & $2 \%$ & $0 \%$ & $5 \%$ & $0 \%$ & $6 \%$ & $0 \%$ & $0.596^{\mathrm{a}}$ \\
\hline Senior colleague & $3 \%$ & $0 \%$ & $10 \%$ & $0 \%$ & $0 \%$ & $8 \%$ & $0.134^{a}$ \\
\hline $\begin{array}{l}\text { Mass media (newspaper, magazine, radio, } \\
\text { television, internet) }\end{array}$ & $7 \%$ & $8 \%$ & $10 \%$ & $16 \%$ & $0 \%$ & $0 \%$ & $0.362^{\mathrm{a}}$ \\
\hline Scientific journals & $1 \%$ & $0 \%$ & $5 \%$ & $0 \%$ & $0 \%$ & $0 \%$ & $0.737^{\mathrm{a}}$ \\
\hline Seminar/conference/symposium & $0 \%$ & $0 \%$ & $0 \%$ & $0 \%$ & $0 \%$ & $0 \%$ & $\mathrm{~N}^{\mathrm{c}}$ \\
\hline \multicolumn{8}{|c|}{ Principles of antibiotic stewardship } \\
\hline $\begin{array}{c}\text { Timely collection of appropriate } \\
\text { specimens for microscopy, culture and } \\
\text { sensitivity }\end{array}$ & $4 \%$ & $8 \%$ & $0 \%$ & $5 \%$ & $0 \%$ & $8 \%$ & $0.551^{\mathrm{a}}$ \\
\hline Using antibiotic only when needed & $5 \%$ & $8 \%$ & $5 \%$ & $0 \%$ & $6 \%$ & $8 \%$ & $0.821^{\mathrm{a}}$ \\
\hline $\begin{array}{l}\text { Choosing the proper antibiotic for specific } \\
\text { infection }\end{array}$ & $7 \%$ & $16 \%$ & $0 \%$ & $11 \%$ & $0 \%$ & $8 \%$ & $0.173^{\mathrm{a}}$ \\
\hline $\begin{array}{l}\text { Timely administration of antibiotics at the } \\
\text { appropriate dose and route }\end{array}$ & $7 \%$ & $8 \%$ & $5 \%$ & $16 \%$ & $0 \%$ & $8 \%$ & $0.515^{\mathrm{a}}$ \\
\hline $\begin{array}{l}\text { Administering antibiotic for appropriate } \\
\text { duration in every case }\end{array}$ & $7 \%$ & $20 \%$ & $5 \%$ & $0 \%$ & $0 \%$ & $8 \%$ & $0.065^{\mathrm{a}}$ \\
\hline Therapeutic monitoring of antibiotic use & $4 \%$ & $8 \%$ & $0 \%$ & $5 \%$ & $00 \%$ & $8 \%$ & $0.551^{\mathrm{a}}$ \\
\hline Improved hygiene and infection control & $3 \%$ & $8 \%$ & $0 \%$ & $0 \%$ & $0 \%$ & $8 \%$ & $0.331^{\mathrm{a}}$ \\
\hline The study of antibiotics & $3 \%$ & $12 \%$ & $0 \%$ & $0 \%$ & $0 \%$ & $0 \%$ & $0.116^{\mathrm{a}}$ \\
\hline
\end{tabular}

$\mathrm{N}^{\mathrm{c}}$ : Not calculable

colleagues, mass media and scientificjournals, respectively. Only $7 \%$ of the respondents agreed that they know the meaning of ABS. Regarding perceptions and knowledge about the principles of $A B S, 4 \%$ of the respondents agreed that $\mathrm{ABS}$ involves therapeutic monitoring of $\mathrm{AB}$ use and timely collection of appropriate specimens for microscopy, culture and sensitivity while $7 \%$ knew that $A B S$ involves choosingthe proper $\mathrm{AB}$, timely administration of $\mathrm{AB}$ at the appropriate dose and route, and administering $\mathrm{AB}$ for appropriate duration in every case. Five percent of the respondents perceived that using $\mathrm{AB}$ only when needed is among the principles of $A B S$ while $3 \%$ of the respondents knew that ABS involves improving hygiene and infection control, and the study of $\mathrm{AB}$.

Perceptionsandattitudes about antibiotic use/prescribing and resistance

Respondents' perceptions and attitude about $\mathrm{AB}$ use/prescribing and resistance is summarized in Table 3. The majority of the respondents (72\%) (range across institutions, $44 \%-100 \% ; P=0.009)$ agreed that $\mathrm{ABR}$ is a global problemwhile far less minority of the respondents (9\%) (range acrossinstitutions, $0 \%-4 \% ; P=0.030$ ) agreed that $\mathrm{ABR}$ is not a significant problem in Nigeria. Concerning factors that promote $\mathrm{ABR}$, slightly above half (55\%) of the respondents agreed that widespread/overuse of
$\mathrm{AB}$ in humans/animals promotes $\mathrm{ABR}$. Very little proportion of the respondents (8\%) knew that poor hand washing practice and poor infection control practices are also contributors to ABR. Minority of the respondents agreed that substandard quality of $\mathrm{ABs}(15 \%)$, administration of inappropriate quantity of $A B$ for inadequate duration (23\%), use of broad-spectrum $\mathrm{AB}$ for treatinganimals when narrow-spectrum is available (26\%) and use/prescription of $\mathrm{ABs}$ by nonveterinarians/professionals (29\%), respectively, are also factors and practices that promote ABR Two-third of the respondents (65\%) agreed that prescribing and use of $A B s$ in veterinaryhospitals are not appropriate in Nigeria. About one-third of the respondents (35\%) agreed that they have prescribed/have been allowed to prescribe $A B$ in their institutional VTH where theyhave rotated while nearly all the respondents (97\%) indicated that antibiograms are rarely used duringprescription in their institutional VTH where they have rotated. Less than one-third (28\%) of the respondents reported that $\mathrm{ABs}$ are overused in their institutional VTH where they have rotated but a majority of the respondents (73\%) reported that ABR is not a significant problem in their institutional VTH where they have rotated. A high proportion of the respondents (78\%) agreed that better use of $A B s$ will reduce problems with ABR and majority of the respondents (73\%) also indicated 
Table 3. Veterinary medical students' perceptions and attitude about antibiotic use and resistance

\begin{tabular}{|c|c|c|c|c|c|c|c|}
\hline \multirow{3}{*}{ Perceptions and attitude } & \multicolumn{6}{|c|}{ Percentage (rounded) of students per university who strongly agree/agree } & \multirow{3}{*}{$P$ Value } \\
\hline & \multicolumn{6}{|c|}{ School } & \\
\hline & All $(\mathrm{n}=95)$ & $\mathrm{A}(\mathrm{n}=25)$ & $\mathrm{B}(\mathrm{n}=20)$ & $\mathrm{C}(\mathrm{n}=19)$ & $\mathrm{D}(\mathrm{n}=18)$ & $E(n=13)$ & \\
\hline $\begin{array}{l}\text { Antibiotic resistance is a global } \\
\text { problem }\end{array}$ & $72 \%$ & $68 \%$ & $70 \%$ & $84 \%$ & $44 \%$ & $100 \%$ & $0.009^{\mathrm{b}}$ \\
\hline $\begin{array}{l}\text { Inappropriate use of antibiotics can directly } \\
\text { harm patients }\end{array}$ & $84 \%$ & $96 \%$ & $70 \%$ & $95 \%$ & $72 \%$ & $85 \%$ & $0.047^{\mathrm{a}}$ \\
\hline $\begin{array}{l}\text { Antibiotic resistance is not a significant } \\
\text { problem in my institutional Veterinary } \\
\text { Teaching Hospital where I have rotated }\end{array}$ & $73 \%$ & $56 \%$ & $70 \%$ & $79 \%$ & $83 \%$ & $85 \%$ & $0.210^{\mathrm{b}}$ \\
\hline $\begin{array}{l}\text { Antibiotic resistance is not a significant } \\
\text { problem in Nigeria }\end{array}$ & $9 \%$ & $4 \%$ & $20 \%$ & $0 \%$ & $22 \%$ & $0 \%$ & $0.030^{2}$ \\
\hline \multicolumn{8}{|c|}{ Contributors/promoters of antibiotic resistance } \\
\hline $\begin{array}{l}\text { Widespread/overuse of antibiotics in } \\
\text { humans and animals }\end{array}$ & $55 \%$ & $48 \%$ & $55 \%$ & $74 \%$ & $61 \%$ & $31 \%$ & $0.168^{\mathrm{b}}$ \\
\hline $\begin{array}{l}\text { Unnecessary use of broad-spectrum } \\
\text { antibiotic for treating animals when narrow- } \\
\text { spectrum antibiotic is available }\end{array}$ & $26 \%$ & $36 \%$ & $30 \%$ & $26 \%$ & $6 \%$ & $31 \%$ & $0.250^{b}$ \\
\hline $\begin{array}{l}\text { Poor hand washing practice by } \\
\text { healthcare/veterinary workers }\end{array}$ & $8 \%$ & $8 \%$ & $5 \%$ & $5 \%$ & $6 \%$ & $23 \%$ & $0.467^{\mathrm{a}}$ \\
\hline $\begin{array}{l}\text { Inadequate farm biosecurity and animal } \\
\text { vaccination }\end{array}$ & $8 \%$ & $12 \%$ & $10 \%$ & $0 \%$ & $11 \%$ & $8 \%$ & $0.624^{\mathrm{a}}$ \\
\hline $\begin{array}{l}\text { Using/prescribing antibiotics by non- } \\
\text { veterinarians/non-professionals }\end{array}$ & $29 \%$ & $32 \%$ & $40 \%$ & $21 \%$ & $28 \%$ & $23 \%$ & $0.741^{\mathrm{b}}$ \\
\hline $\begin{array}{l}\text { Administering inadequate antibiotic doses } \\
\text { for inappropriate frequency }\end{array}$ & $23 \%$ & $48 \%$ & $20 \%$ & $16 \%$ & $6 \%$ & $15 \%$ & $0.017^{\mathrm{a}}$ \\
\hline $\begin{array}{l}\text { Prescribing and using substandard quality of } \\
\text { antibiotics to treat animals }\end{array}$ & $15 \%$ & $16 \%$ & $20 \%$ & $21 \%$ & $11 \%$ & $0 \%$ & $0.465^{\mathrm{a}}$ \\
\hline \multicolumn{8}{|c|}{ Antibiotic use attitudes in veterinary settings } \\
\hline $\begin{array}{c}\text { Prescribing and use of antibiotics in } \\
\text { veterinary hospitals in Nigeria are not } \\
\text { appropriate }\end{array}$ & $65 \%$ & $64 \%$ & $60 \%$ & $89 \%$ & $50 \%$ & $62 \%$ & $0.133^{b}$ \\
\hline $\begin{array}{l}\text { I have prescribed or have been allowed to } \\
\text { prescribe antibiotic in my institutional } \\
\text { Veterinary Teaching Hospital where I have } \\
\text { rotated }\end{array}$ & $35 \%$ & $32 \%$ & $20 \%$ & $47 \%$ & $28 \%$ & $54 \%$ & $0.219^{\mathrm{b}}$ \\
\hline $\begin{array}{l}\text { Antibiograms are rarely used during } \\
\text { prescription in my institutional Veterinary } \\
\text { Teaching Hospital where I have rotated }\end{array}$ & $97 \%$ & $96 \%$ & $100 \%$ & $89 \%$ & $100 \%$ & $100 \%$ & $0.362^{\mathrm{a}}$ \\
\hline $\begin{array}{l}\text { Antibiotics are overused in my institutional } \\
\text { Veterinary Teaching Hospital where I have } \\
\text { rotated }\end{array}$ & $28 \%$ & $40 \%$ & $35 \%$ & $37 \%$ & $11 \%$ & $8 \%$ & $0.087^{\mathrm{b}}$ \\
\hline $\begin{array}{l}\text { Better use of antibiotic will reduce problems } \\
\text { with antibiotic resistance }\end{array}$ & $78 \%$ & $76 \%$ & $80 \%$ & $74 \%$ & $67 \%$ & $100 \%$ & $0.206^{\mathrm{a}}$ \\
\hline $\begin{array}{l}\text { I would like more education on antibiotic } \\
\text { resistance }\end{array}$ & $73 \%$ & $84 \%$ & $70 \%$ & $89 \%$ & $61 \%$ & $77 \%$ & $0.258^{\mathrm{a}}$ \\
\hline \multicolumn{8}{|c|}{ Factors that could influence my decision to prescribe antibiotic } \\
\hline Client pressure/push & $18 \%$ & $8 \%$ & $45 \%$ & $11 \%$ & $17 \%$ & $8 \%$ & $0.020^{2}$ \\
\hline Health status/condition of the patient & $37 \%$ & $20 \%$ & $50 \%$ & $21 \%$ & $56 \%$ & $46 \%$ & $0.043^{b}$ \\
\hline Peers (other students) & $8 \%$ & $8 \%$ & $5 \%$ & $11 \%$ & $11 \%$ & $8 \%$ & $0.964^{2}$ \\
\hline Senior colleague & $11 \%$ & $8 \%$ & $20 \%$ & $5 \%$ & $6 \%$ & $15 \%$ & $0.541^{2}$ \\
\hline Antibiogram of isolates & $52 \%$ & $68 \%$ & $10 \%$ & $68 \%$ & $50 \%$ & $62 \%$ & $<0.001$ \\
\hline Cost of antibiotic & $37 \%$ & $52 \%$ & $10 \%$ & $63 \%$ & $28 \%$ & $23 \%$ & $0.002^{b}$ \\
\hline Profit to be made & $15 \%$ & $16 \%$ & $25 \%$ & $5 \%$ & $17 \%$ & $8 \%$ & $0.487^{\mathrm{a}}$ \\
\hline Ensure therapeutic success & $40 \%$ & $32 \%$ & $50 \%$ & $42 \%$ & $44 \%$ & $31 \%$ & $0.716^{b}$ \\
\hline \multicolumn{8}{|c|}{ Troublesome resistant zoonotic bacteria of public health concern } \\
\hline Staphylococcus aureus & $39 \%$ & $44 \%$ & $65 \%$ & $11 \%$ & $33 \%$ & $38 \%$ & $0.013^{b}$ \\
\hline Pseudomonas aeruginosa & $17 \%$ & $24 \%$ & $35 \%$ & $0 \%$ & $11 \%$ & $8 \%$ & $0.024^{a}$ \\
\hline Klebsiella pneumoniae & $6 \%$ & $16 \%$ & $5 \%$ & $5 \%$ & $0 \%$ & $0 \%$ & $0.278^{\mathrm{a}}$ \\
\hline Enterococcus faecium & $4 \%$ & $4 \%$ & $5 \%$ & $5 \%$ & $6 \%$ & $0 \%$ & $1.000^{2}$ \\
\hline Clostridium difficile & $13 \%$ & $16 \%$ & $10 \%$ & $0 \%$ & $33 \%$ & $0 \%$ & $0.017^{\mathrm{a}}$ \\
\hline
\end{tabular}


that they would like more education on ABR

Regarding factors that could influence the respondent's prescription of $\mathrm{AB}, 18 \%$ (range across institutions, $8 \% 45 \%$; $P=0.020$ ) agreed that their client could influence them, $37 \%$ reported that the health status/condition of the animal (range across institutions, 20\%-56\%; $P=0.043$ ) and cost of $\mathrm{AB}$ (range across institution, $10 \%-63 \% ; P=0.002$ ) could influence their prescription, slightly above half of the respondents (52\%) (range across institutions, $10 \%-68 \%$; $P$ $<0.001$ ) reported that antibiogram of the isolate could influence them, while $8 \%, 10 \%, 14 \%$ and $40 \%$ agreed that peers, senior colleague(s), profit to be made, and ensuring therapeutic success, are factors that could influence their prescription of $\mathrm{AB}$ (Table 3 ).

With regards to perceptions/knowledge about zoonotic resistant bacteria of public health concern, 39\% (range across institutions, $11 \%-44 \% ; P=0.013$ ) of the respondents recognized Staphylococcus aureus, Pseudomonas aeruginosa $17 \%$ (range across institutions, $0 \%-35 \% ; P=0.024$ ), and Clostridium difficile 13\% (range across institutions, $0 \%$ $33 \% ; P=0.017$ ) (Table 3). Far less minority of the respondents agreed that Klebsiella pneumoniae (6\%) and Enterococcus faecium (4\%) are also problematic zoonotic resistant bacteria.

Perceptionsandknowledge about goals and development strategies of antibiotic stewardship

The respondents' perceptions about goals and development strategies of ABS are summarized in Table 4. Concerning the goals of $A B S$, minority of the respondents knew that ABS seek to reduce hospital stay (2\%), reduce $\operatorname{ABR}(17 \%)$, and minimize toxicity and otheradverse effects (6\%). Very minimal proportion of the respondents agreed that $\mathrm{ABS}$ seek to increase the use of broad-spectrum $\mathrm{AB}$ (1\%) and increase duration of therapy to ensure therapeutic success $(2 \%)$ whereas none of the respondent agreed that increasing the use of $\mathrm{AB}$ is among the goals of $\mathrm{ABS}$.

Regarding the development strategies of $A B S$, minority of the respondents (19\%) agreed that assembling and leading of the core ABS team is one of the responsibilities of the veterinarians in ASPs. None of the respondent agreed that ASP exist for veterinary hospitals in Nigeria. For the formation of $\mathrm{ABS}$ team, low proportion of the respondents agreed that veterinarians $(19 \%)$, veterinary assistants $(5 \%)$, physicians $(9 \%)$,veterinary hospital pharmacists $(13 \%)$ and infection control staffs (8\%), are members of ABS team. There was also agreement by a minority of the respondents $(13 \%)$ that hospital cleaning staffs are members of ABS team but with significantvariation $(P<0.001$; range across institutions, $0 \%-50 \%)$ in responses of the respondents. Pertaining to the role of veterinarians in $\mathrm{ABS}$, prescribing $\mathrm{AB}$ over-the-counter was thought to be the major role of veterinarians $(69 \%)$ whereas promoting optimal use of antibiotic (15\%), educating veterinary allied healthcare professionals (13\%) and working with therapeutic committees to develop policies (7\%), were regarded as the minor roles of veterinarians in ASPs.

Regarding interventions that could help in curbing $A B R$, majority of the respondents (92\%) agreed that the establishment and implementation of ASPs in veterinary hospitals are essential in Nigeria while less than half of the respondents agreed that education on $\mathrm{AB}$ therapy (44\%) and development of $\mathrm{AB}$ usage policies (35\%) are useful interventions to contain $\mathrm{ABR}$ (Table 4). Less than onethird of the respondents agreed that reduction of $A B$ use (14\%), establishment of national $\mathrm{AB}$ resistance surveillance (28\%) and developmentof institutional guidelines for $\mathrm{AB}$ use (29\%), are interventions to curb ABR. Majority of the respondents (84\%) agreed that inappropriate use of $A B$ can harm patients although with significant difference in responsesbetween the schools (range across institutions, $70 \%-96 \% ; P=0.047)$. Only half of the respondents $(51 \%)$ agreed that avoidance of treating self-limiting infections reduces ABR. High proportion of the respondents (88\%) agreed that strong knowledge of $A B$ is important for their future veterinarycareer and teaching about $A B R$ and $A B S$ at all levels of veterinary education will enhance appropriate use of $A B$ by veterinarians. Majority of the respondents (71\%) agreed that new AB will be developed in the future that will keep up with the problem of $A B R$.

\section{Perceptionsabouteducation on appropriate antibiotic use} and stewardship preparedness

Respondents' perception about the quality and quantity of their ABS education and ABS preparedness is summarized in Table 5. Overall, minority of the respondents (12\%) agreed theyhave had formal lecture on ABS for 1-4 hours whereas most of them (88\%) reported that they have never had any formal training on ABS. None of the respondents agreed to have ever had ABS training for 5 hours. A low proportion of the respondents (17\%) were confident that what they were taught on $A B R$ resistance is enough for their veterinary career while most of them (84\%) indicated that they would like more training on $\mathrm{ABS}$.

Regarding topics on $\mathrm{AB}$ and $\mathrm{AB}$ therapy, 68 out of 95 (72\%) of the students recalled that spectrum of therapy for different $A B$ have been taught very well with significant variation in responses between the schools (range across institutions, $56 \%-96 \% ; P=0.020)$. Most of the respondents agreed that their education about the basic mechanisms of $\mathrm{ABR}(74 \%)$ and how to select the best $\mathrm{AB}$ for specific infection was good/very good. Less than two-third (59\%) of the respondents also believed that their education about how to find reliable information to treat patients, when to start $\mathrm{AB}$ therapy (57\%), and how to interpret antibiograms (60\%) was good/verygood while less than one-third lacked confidence about their education on transitioning from intravenous to oral $\mathrm{ABs}(27 \%)$, streamlining/de-escalating $A B$ therapy $(19 \%)$ and handling clients demanding unnecessary $\mathrm{AB}$ for their animals (41\%).

\section{Educational resources used for learning about antibiotic} use and resistance

Sources of information about $\mathrm{AB}$ use and resistance used by the respondents are summarized in Table 6 . The sources of information used by the respondents were, in rank of decreasing frequency: iPhone/Smart phone applications (36\%), lecturers/resident doctors (25\%)(range across schools, $\quad 0 \%-40 \% ; \quad P=0.014), \quad$ textbooks /Merck's/Black's veterinary manual (17\%), class lecture notes $(16 \%)$ (range across schools, $0 \%-35 \% ; P=0.010$ ), Nigerian veterinary formulary (14\%), medical/veterinary journals (12\%) (range acrossschools, $0 \%-24 \% ; P=0.023$ ), Wikipedia (8\%), peers (other students) (5\%), veterinary hospital pharmacists (3\%) and veterinary assistants (2\%). 
162

Table 4. Veterinary medical students' perceptions and knowledge about goals and development strategies of antibiotic stewardship

\begin{tabular}{|c|c|c|c|c|c|c|c|}
\hline \multirow{3}{*}{$\begin{array}{l}\text { Goals and development strategies of } \\
\text { antibiotic stewardship }\end{array}$} & \multicolumn{6}{|c|}{ Percentage (rounded) of students per university who strongly agree/agree } & \multirow{3}{*}{$P$ Value } \\
\hline & \multicolumn{6}{|c|}{ School } & \\
\hline & All $(n=95)$ & $\mathrm{A}(\mathrm{n}=25)$ & $\mathrm{B}(\mathrm{n}=20)$ & $\mathrm{C}(\mathrm{n}=19)$ & $\mathrm{D}(\mathrm{n}=18)$ & $E(n=13)$ & \\
\hline \multicolumn{8}{|c|}{ Goals of antibiotic stewardship } \\
\hline Increasing the use of antibiotics & $0 \%$ & $0 \%$ & $0 \%$ & $0 \%$ & $0 \%$ & $0 \%$ & $\mathrm{~N}^{\mathrm{c}}$ \\
\hline Reducing hospital stay & $2 \%$ & $0 \%$ & $10 \%$ & $0 \%$ & $0 \%$ & $0 \%$ & $0.133^{\mathrm{a}}$ \\
\hline $\begin{array}{l}\text { Increasing duration of therapy to ensure } \\
\text { therapeutic success }\end{array}$ & $2 \%$ & $0 \%$ & $5 \%$ & $0 \%$ & $0 \%$ & $8 \%$ & $0.299^{\mathrm{a}}$ \\
\hline $\begin{array}{l}\text { Increasing use of broad-spectrum } \\
\text { antibiotics }\end{array}$ & $1 \%$ & $4 \%$ & $0 \%$ & $0 \%$ & $0 \%$ & $0 \%$ & $1.000^{\mathrm{a}}$ \\
\hline Reducing antibiotic resistance & $17 \%$ & $20 \%$ & $15 \%$ & $21 \%$ & $6 \%$ & $23 \%$ & $0.630^{\mathrm{a}}$ \\
\hline $\begin{array}{l}\text { Minimizing toxicity and other adverse } \\
\text { effects }\end{array}$ & $6 \%$ & $4 \%$ & $5 \%$ & $11 \%$ & $6 \%$ & $8 \%$ & $0.945^{\mathrm{a}}$ \\
\hline \multicolumn{8}{|c|}{ Members of the antibiotic stewardship team } \\
\hline Physicians & $9 \%$ & $20 \%$ & $5 \%$ & $11 \%$ & $6 \%$ & $0 \%$ & $0.351^{a}$ \\
\hline Veterinary assistants & $5 \%$ & $12 \%$ & $5 \%$ & $0 \%$ & $6 \%$ & $0 \%$ & $0.534^{\mathrm{a}}$ \\
\hline Veterinary hospital pharmacists & $13 \%$ & $24 \%$ & $5 \%$ & $16 \%$ & $11 \%$ & $0 \%$ & $0.221^{\mathrm{a}}$ \\
\hline Infection control staff & $8 \%$ & $12 \%$ & $5 \%$ & $11 \%$ & $11 \%$ & $0 \%$ & $0.775^{a}$ \\
\hline Veterinary clinical microbiologist & $5 \%$ & $12 \%$ & $5 \%$ & $0 \%$ & $6 \%$ & $0 \%$ & $0.534^{\mathrm{a}}$ \\
\hline Veterinary hospital cleaning staff & $13 \%$ & $12 \%$ & $0 \%$ & $0 \%$ & $50 \%$ & $0 \%$ & $<0.001$ \\
\hline Veterinarians & $19 \%$ & $24 \%$ & $5 \%$ & $16 \%$ & $28 \%$ & $23 \%$ & $0.340^{\mathrm{a}}$ \\
\hline \multicolumn{8}{|c|}{ Roles of veterinarians in antibiotic stewardship } \\
\hline $\begin{array}{l}\text { Assembling and leading of the core } \\
\text { antibiotic stewardship team }\end{array}$ & $19 \%$ & $16 \%$ & $5 \%$ & $21 \%$ & $33 \%$ & $23 \%$ & $0.234^{\mathrm{a}}$ \\
\hline Promoting optimal use of antimicrobials & $15 \%$ & $12 \%$ & $10 \%$ & $21 \%$ & $17 \%$ & $15 \%$ & $0.871^{\mathrm{a}}$ \\
\hline $\begin{array}{l}\text { Educating veterinary allied healthcare } \\
\text { professionals/public }\end{array}$ & $13 \%$ & $12 \%$ & $5 \%$ & $21 \%$ & $11 \%$ & $15 \%$ & $0.650^{\mathrm{a}}$ \\
\hline $\begin{array}{l}\text { Working with therapeutic committees to } \\
\text { develop policies }\end{array}$ & $7 \%$ & $8 \%$ & $10 \%$ & $5 \%$ & $11 \%$ & $0 \%$ & $0.852^{\mathrm{a}}$ \\
\hline Prescribing antibiotics over-the-counter & $69 \%$ & $48 \%$ & $85 \%$ & $79 \%$ & $67 \%$ & $77 \%$ & $0.062^{b}$ \\
\hline \multicolumn{8}{|c|}{ Interventions that can help in combating antibiotic resistance } \\
\hline Development of antibiotic usage policies & $35 \%$ & $40 \%$ & $50 \%$ & $26 \%$ & $33 \%$ & $15 \%$ & $0.283^{\mathrm{b}}$ \\
\hline Reduction of antibiotic use & $14 \%$ & $16 \%$ & $25 \%$ & $11 \%$ & $11 \%$ & $0 \%$ & $0.373^{\mathrm{a}}$ \\
\hline $\begin{array}{l}\text { Establishment of national antibiotic } \\
\text { resistance surveillance }\end{array}$ & $28 \%$ & $36 \%$ & $40 \%$ & $11 \%$ & $28 \%$ & $23 \%$ & $0.274^{b}$ \\
\hline $\begin{array}{l}\text { Development of institutional guidelines for } \\
\text { antibiotic use }\end{array}$ & $29 \%$ & $32 \%$ & $40 \%$ & $16 \%$ & $17 \%$ & $46 \%$ & $0.201^{\mathrm{b}}$ \\
\hline Education on antibiotic therapy & $44 \%$ & $56 \%$ & $40 \%$ & $37 \%$ & $44 \%$ & $38 \%$ & $0.723^{b}$ \\
\hline $\begin{array}{l}\text { Antibiotic stewardship programme exist for } \\
\text { veterinary dinics/hospitals in Nigeria }\end{array}$ & $0 \%$ & $0 \%$ & $0 \%$ & $0 \%$ & $0 \%$ & $0 \%$ & $\mathrm{~N}^{\mathrm{c}}$ \\
\hline $\begin{array}{l}\text { Establishment and implementation of } \\
\text { antibiotic stewardship programmes in } \\
\text { veterinary hospitals are essential in Nigeria }\end{array}$ & $92 \%$ & $92 \%$ & $90 \%$ & $89 \%$ & $89 \%$ & $100 \%$ & $0.863^{\mathrm{a}}$ \\
\hline $\begin{array}{c}\text { Avoidance of treating self-limiting } \\
\text { infections in animals reduces antibiotic } \\
\text { resistance }\end{array}$ & $51 \%$ & $40 \%$ & $50 \%$ & $74 \%$ & $56 \%$ & $23 \%$ & $0.055^{\mathrm{b}}$ \\
\hline $\begin{array}{l}\text { Teaching about antibiotic resistance and } \\
\text { stewardship at all levels of veterinary } \\
\text { education will enhance appropriate use of } \\
\text { antibiotics by veterinarians }\end{array}$ & $88 \%$ & $96 \%$ & $75 \%$ & $84 \%$ & $78 \%$ & $92 \%$ & $0.242^{\mathrm{a}}$ \\
\hline $\begin{array}{l}\text { Strong knowledge of antibiotics is } \\
\text { important for my future veterinary career }\end{array}$ & $88 \%$ & $92 \%$ & $80 \%$ & $84 \%$ & $78 \%$ & $92 \%$ & $0.645^{\mathrm{a}}$ \\
\hline $\begin{array}{l}\text { New antibiotics will be developed in the } \\
\text { future that will keep up with the problem of } \\
\text { antibiotic resistance }\end{array}$ & $71 \%$ & $68 \%$ & $70 \%$ & $68 \%$ & $72 \%$ & $77 \%$ & $0.984^{b}$ \\
\hline
\end{tabular}


Table 5. Veterinary medical students' perceptions of their antibiotic stewardship education and preparedness

\begin{tabular}{|c|c|c|c|c|c|c|c|}
\hline \multirow{3}{*}{ Perceptions } & \multicolumn{6}{|c|}{ Percentage (rounded) of students per university who strongly agree/agree } & \multirow{3}{*}{$P$ Value } \\
\hline & \multicolumn{6}{|c|}{ School } & \\
\hline & All $(\mathrm{n}=95)$ & $\mathrm{A}(\mathrm{n}=25)$ & $\mathrm{B}(\mathrm{n}=20)$ & $\mathrm{C}(\mathrm{n}=19)$ & $\mathrm{D}(\mathrm{n}=18)$ & $E(n=13)$ & \\
\hline $\begin{array}{l}\text { I have attended a formal lecture on antibiotic } \\
\text { stewardship }\end{array}$ & $12 \%$ & $16 \%$ & $20 \%$ & $5 \%$ & $6 \%$ & $8 \%$ & $0.573^{\mathrm{a}}$ \\
\hline $\begin{array}{l}\text { I have attended a } 1-4 \text { hour antibiotic } \\
\text { stewardship lecture or training }\end{array}$ & $12 \%$ & $16 \%$ & $20 \%$ & $5 \%$ & $6 \%$ & $8 \%$ & $0.573^{\mathrm{a}}$ \\
\hline $\begin{array}{c}\text { I have attended antimicrobial stewardship } \\
\text { lecture/training that lasted more than } 5 \\
\text { hours }\end{array}$ & $0 \%$ & $0 \%$ & $0 \%$ & $0 \%$ & $0 \%$ & $0 \%$ & $\mathrm{~N}^{c}$ \\
\hline $\begin{array}{l}\text { I have had no formal antibiotic stewardship } \\
\text { lecture/training }\end{array}$ & $88 \%$ & $84 \%$ & $80 \%$ & $95 \%$ & $94 \%$ & $92 \%$ & $0.573^{\mathrm{a}}$ \\
\hline $\begin{array}{l}\text { What I have been taught on antibiotic } \\
\text { resistance in the veterinary school is enough } \\
\text { for my future veterinary career }\end{array}$ & $17 \%$ & $16 \%$ & $20 \%$ & $5 \%$ & $28 \%$ & $15 \%$ & $0.481^{\mathrm{a}}$ \\
\hline $\begin{array}{l}\text { I would like to be trained/more training on } \\
\text { antibiotic stewardship }\end{array}$ & $87 \%$ & $96 \%$ & $75 \%$ & $89 \%$ & $78 \%$ & $100 \%$ & $0.093^{\mathrm{a}}$ \\
\hline \multicolumn{8}{|c|}{ Antibiotic stewardship activity understood very well and considered useful for my career } \\
\hline $\begin{array}{c}\text { Finding reliable information to treat my } \\
\text { patients }\end{array}$ & $59 \%$ & $64 \%$ & $55 \%$ & $79 \%$ & $56 \%$ & $31 \%$ & $0.097^{\mathrm{b}}$ \\
\hline Basic mechanisms of antibiotic resistance & $74 \%$ & $88 \%$ & $70 \%$ & $68 \%$ & $61 \%$ & $77 \%$ & $0.337^{\mathrm{a}}$ \\
\hline $\begin{array}{l}\text { Handling clients demanding unnecessary } \\
\text { antibiotics for their animals }\end{array}$ & $41 \%$ & $36 \%$ & $55 \%$ & $47 \%$ & $39 \%$ & $23 \%$ & $0.424^{\mathrm{a}}$ \\
\hline $\begin{array}{l}\text { When to start antibiotic therapy in sick } \\
\text { animals }\end{array}$ & $57 \%$ & $60 \%$ & $70 \%$ & $42 \%$ & $61 \%$ & $46 \%$ & $0.423^{b}$ \\
\hline $\begin{array}{l}\text { Selecting appropriate antibiotic for specific } \\
\text { infection }\end{array}$ & $79 \%$ & $92 \%$ & $70 \%$ & $84 \%$ & $78 \%$ & $62 \%$ & $0.166^{a}$ \\
\hline $\begin{array}{l}\text { Identifying spectrum of therapy for different } \\
\text { antibiotics }\end{array}$ & $72 \%$ & $96 \%$ & $70 \%$ & $58 \%$ & $56 \%$ & $69 \%$ & $0.020^{\mathrm{b}}$ \\
\hline Interpreting antibiograms & $60 \%$ & $76 \%$ & $60 \%$ & $47 \%$ & $50 \%$ & $62 \%$ & $0.330^{\mathrm{b}}$ \\
\hline $\begin{array}{c}\text { Transitioning from intravenous to oral } \\
\text { antibiotics }\end{array}$ & $27 \%$ & $28 \%$ & $45 \%$ & $21 \%$ & $28 \%$ & $8 \%$ & $0.209^{b}$ \\
\hline $\begin{array}{c}\text { Streamlining/de-escalating antibiotic } \\
\text { therapy }\end{array}$ & $19 \%$ & $20 \%$ & $35 \%$ & $21 \%$ & $11 \%$ & $0 \%$ & $0.126^{\mathrm{a}}$ \\
\hline
\end{tabular}

${ }^{b} \chi^{2}$ test; $N^{c}$ : Not calculable

Table 6. Resources used for learning about antibiotic use/prescribing and resistance

\begin{tabular}{|c|c|c|c|c|c|c|c|}
\hline \multirow{3}{*}{ Resource } & \multicolumn{6}{|c|}{$\begin{array}{l}\text { Percentage (rounded) of students per university who agree to have } \\
\text { often/sometimes/occasionally used the resource }\end{array}$} & \multirow{3}{*}{$P$ Value } \\
\hline & \multicolumn{6}{|c|}{ School } & \\
\hline & All $(\mathrm{n}=95)$ & $\mathrm{A}(\mathrm{n}=25)$ & $\mathrm{B}(\mathrm{n}=20)$ & $C(n=19)$ & $\mathrm{D}(\mathrm{n}=18)$ & $E(n=13)$ & \\
\hline $\begin{array}{l}\text { iPhone/Smartphone } \\
\text { applications }\end{array}$ & $36 \%$ & $28 \%$ & $35 \%$ & $42 \%$ & $50 \%$ & $23 \%$ & $0.490^{\mathrm{b}}$ \\
\hline Nigerian veterinary formulary & $14 \%$ & $8 \%$ & $15 \%$ & $32 \%$ & $6 \%$ & $8 \%$ & $0.177^{a}$ \\
\hline Veterinary hospital pharmacists & $3 \%$ & $4 \%$ & $5 \%$ & $0 \%$ & $0 \%$ & $8 \%$ & $0.755^{a}$ \\
\hline Veterinary assistants & $2 \%$ & $0 \%$ & $5 \%$ & $5 \%$ & $0 \%$ & $0 \%$ & $0.681^{a}$ \\
\hline Lecturers/Resident doctors & $25 \%$ & $36 \%$ & $40 \%$ & $0 \%$ & $22 \%$ & $23 \%$ & $0.014^{\mathrm{a}}$ \\
\hline Medical/Veterinary journals & $12 \%$ & $24 \%$ & $5 \%$ & $0 \%$ & $22 \%$ & $0 \%$ & $0.023^{\mathrm{a}}$ \\
\hline Textbook/Merck's Veterinary & & & & & & & \\
\hline $\begin{array}{l}\text { Manual/Black's Veterinary } \\
\text { Manual }\end{array}$ & $17 \%$ & $16 \%$ & $30 \%$ & $11 \%$ & $17 \%$ & $8 \%$ & $0.507^{a}$ \\
\hline Peers (other students) & $5 \%$ & $4 \%$ & $10 \%$ & $0 \%$ & $11 \%$ & $0 \%$ & $0.439^{\mathrm{a}}$ \\
\hline Class lecture notes & $16 \%$ & $16 \%$ & $35 \%$ & $0 \%$ & $22 \%$ & $0 \%$ & $0.010^{\mathrm{a}}$ \\
\hline Wikipedia & $8 \%$ & $4 \%$ & $20 \%$ & $0 \%$ & $11 \%$ & $8 \%$ & $0.191^{\mathrm{a}}$ \\
\hline
\end{tabular}

a'Fischer's exact test
${ }^{\mathrm{b}} \chi^{2}$ test 
164

Students' mean correct knowledge scorefor the clinical vignettes was $29 \%$ with no statistical significance in responsesbetween the study sites. The concepts assessed and scores are shown in Table 7. Respondents scored fairly highly on questions dealing with identification of scenarios with potential for unnecessary use of $A B$ in animals (68\%), recognizing the possible risks associated with unnecessary use of $\mathrm{AB}$ in animals (62\%) and recognition of spectrum of activity of selected $\mathrm{AB}$ (56\%), but poorly on questions regarding recognition of critically-important $\mathrm{AB}$ for human use (9\%), treating ESBL-resistant infections in companion animals (11\%), recognition of Clostridium difficile infection (25\%), determination of antibiogram of colistin-resistant enterobacterial isolates (2\%), treating complicated urinary tract infection in companion animals (19\%), and mechanisms of resistance of bacteria of zoonotic public health importance (13-23\%). Suboptimal scores were recorded for Escherichia coli/ß-lactam resistance (23\%), Staphylococcus aureus/methicillin resistance (28\%) and Enterococcus/cephalosporin (13\%).

Table 7. Summary of knowledge vignettes with corresponding proportion of correct responses byveterinary schools

\begin{tabular}{|c|c|c|c|c|c|c|c|}
\hline \multirow{3}{*}{ Clinical vignettes } & \multicolumn{6}{|c|}{ Percentage (rounded) of students per university who showed correct competency } & \multirow{3}{*}{$P$ Value } \\
\hline & \multicolumn{6}{|c|}{ School } & \\
\hline & All $(n=95)$ & $\mathrm{A}(\mathrm{n}=25)$ & $\mathrm{B}(\mathrm{n}=20)$ & $C(n=19)$ & $\mathrm{D}(\mathrm{n}=18)$ & $\mathrm{E}(\mathrm{n}=13)$ & \\
\hline $\begin{array}{l}\text { Identify scenarios with potential for unnecessary } \\
\text { use of antibiotics in animals }\end{array}$ & $68 \%$ & $72 \%$ & $80 \%$ & $74 \%$ & $44 \%$ & $69 \%$ & $0.173^{\mathrm{b}}$ \\
\hline $\begin{array}{l}\text { Recognize the possible risks associated with } \\
\text { unnecessary use of antibiotics in animals }\end{array}$ & $62 \%$ & $64 \%$ & $50 \%$ & $58 \%$ & $67 \%$ & $77 \%$ & $0.603^{\mathrm{b}}$ \\
\hline $\begin{array}{l}\text { Recognize Clostridium difficile infection in } \\
\text { humans/animals secondary to the use of } \\
\text { antibiotics }\end{array}$ & $25 \%$ & $20 \%$ & $25 \%$ & $37 \%$ & $17 \%$ & $31 \%$ & $0.637^{\mathrm{b}}$ \\
\hline $\begin{array}{l}\text { Recognize the spectrum of activity of selected } \\
\text { antibiotic }\end{array}$ & $56 \%$ & $40 \%$ & $55 \%$ & $58 \%$ & $67 \%$ & $77 \%$ & $0.222^{b}$ \\
\hline $\begin{array}{l}\text { Colistin-resistant enterobacterial diarrhoea: } \\
\text { appropriate antibiotic susceptibility test }\end{array}$ & $2 \%$ & $4 \%$ & $0 \%$ & $0 \%$ & $6 \%$ & $0 \%$ & $0.782^{\mathrm{a}}$ \\
\hline $\begin{array}{l}\text { Recognize critically-important antibiotics for } \\
\text { human use }\end{array}$ & $9 \%$ & $8 \%$ & $10 \%$ & $5 \%$ & $17 \%$ & $8 \%$ & $0.845^{\mathrm{a}}$ \\
\hline $\begin{array}{l}\text { Extended-spectrum } \beta \text {-lactamases-producing } \\
\text { Escherichia coli bacteraemia in companion } \\
\text { animals: antibiotic selection }\end{array}$ & $11 \%$ & $8 \%$ & $15 \%$ & $11 \%$ & $11 \%$ & $8 \%$ & $0.985^{\mathrm{a}}$ \\
\hline $\begin{array}{l}\text { Complicated urinary tract infection in } \\
\text { companion animals: appropriate antibiotic } \\
\text { selection and duration of treatment }\end{array}$ & $19 \%$ & $20 \%$ & $25 \%$ & $21 \%$ & $11 \%$ & $15 \%$ & $0.878^{\mathrm{a}}$ \\
\hline E. coli/ß-lactam resistance & $23 \%$ & $24 \%$ & $20 \%$ & $21 \%$ & $22 \%$ & $23 \%$ & $1.000^{\mathrm{a}}$ \\
\hline Staphylococcus aureus/methicillin resistance & $28 \%$ & $32 \%$ & $40 \%$ & $32 \%$ & $17 \%$ & $15 \%$ & $0.436^{\mathrm{b}}$ \\
\hline Enterococcus/cephalosporin & $13 \%$ & $12 \%$ & $15 \%$ & $16 \%$ & $11 \%$ & $8 \%$ & $0.722^{\mathrm{a}}$ \\
\hline Overall for all questions & $29 \%$ & $28 \%$ & $30 \%$ & $30 \%$ & $26 \%$ & $30 \%$ & $0.232^{\mathrm{a}}$ \\
\hline
\end{tabular}

$\chi^{2}$ test

\section{Discussion}

This is the first assessment of Nigerian veterinary medical students' perception about ABRand ABSand their preparedness for appropriate use of $\mathrm{ABs}$, and to our knowledge it is the first of such report in Africa. In Nigeria, a fresh VM graduate is expected to start prescribing drugs from inception of a compulsory one year national youth service, thus every Nigerian veterinarian is a potential prescriberand dispenser of $\mathrm{AB}$ (Fairles, 2013; Anyanwu and Kolade, 2017), and there arelimited opportunities (if there is any) for postgraduate training in $\mathrm{ABS}$, particularly outside the academic setting (Wasserman et al., 2017). Further, there is no residency (house job/internship) programme for fresh VM graduates, and veterinarians (most of which have no experience/skill on graduation) are allowed to start prescribing (with or without supervision by senior veterinarians) and dispensing $\mathrm{AB}$ immediately on graduation from veterinary schools (Anyanwu and Kolade, 2017). Given the importance of veterinarians as key partners in ABS efforts, VMS should therefore be knowledgeable about ABR and ABS (Brink et al., 2017). In this study, 3 major findings which are similar with those of multicentre studies(Minen et al., 2010; Abbo et al., 2013; Dyar et al., 2014; Justo et al., 2014; Burger et al., 2016; Ferdoush etal., 2016; Yang et al., 2016; Wasserman et al., 2017) conducted among medical/pharmacy students in developed and developing countries were made:(i) low level of knowledge about ABR and ABS, (ii) perceived lack of preparedness to practice ABS and lead in ASPs, and (iii) desire for more education about ABR and ABS. 
The result of this study revealed that a very minimal proportion (7\%) of Nigerian veterinary students may know the meaning of ABS. Burger et al. (2015) reported that $83.5 \%$ among 260 final-year pharmacy students in 3 South African Universities knew the meaning of antimicrobial stewardship (AMS). Thelowlevel of knowledge about ABS in this study is attributed to the fact that very few (17\%) of the respondents in thisstudy have heard of ABS. Ferdoush et al. (2016) reported that $6 \%$ among 1714 th-year students in 3 Bangladeshi medical schools were familiar with the term AMS while less than two-third of 289 final-year students in 3 South African medical schools reported familiarity with the term ABS (Wasserman et al., 2017). Anyanwu and Kolade (2017) reported that $17.1 \%$ among 280 practicing/teaching veterinarians in Enugu State Nigeria haveheard of ABS. The disparities in these studies may be due to differencesin ABS awarenesseducation that has been conducted in the various health profession institutions, degree of integration in the curricula and teaching of AMS education in the institutions, and/or the degree of AMS education awareness that has been conducted via sources such as mass media, journals, peers, etc in the study area (Lee et al., 2015; Anyanwu and Kolade, 2017). Among the NVS that reported familiarity with the term ABS, highest number reported that they heard about ABS from their lecturer while a very minority of them heard/learnt of ABS from their peers, senior colleagues, mass media and/orscientificjournals (Lee et al., 2015). The low awareness about ABSobserved in this study, suggested that there is little or no effort in Nigeria to educate veterinary studentsabout $A B S$ and there is also little or no ABS education awareness in form of seminars, symposium, radio jingles, etc in Nigeria (Lee et al., 2015). It also suggested that the curricula of Nigerian veterinary medical schools might be deficient on issues of ABS (Anyanwu and Kolade, 2017).

Regarding background knowledge and perceptions of $A B S$, it is very worrisome that very minimal proportion of NVS (7\%) knew that ABS involves therapeutic monitoring of $A B$ use, timely collection of appropriate specimens for microscopy, culture and sensitivity, choosing the proper $\mathrm{AB}$, timely administration of $\mathrm{AB}$ at the appropriate dose and route, administering $\mathrm{AB}$ for appropriate duration in every case, using $\mathrm{AB}$ only when needed, improving hygiene and infection control, and the study of $\mathrm{AB}$ ( $\mathrm{O}^{\circ}$ Donnell and Guarascio, 2017). This finding contrasts Burger et al. (2016) that 50.4\%-95\% (range for the principles) among pharmacy students in South Africa, knew that ABS involved the above principles. Variation in the perceptions of students in these studies maybe attributed to differences in exposure to $\mathrm{ABS}$ in the various institutions and/or study area (Thriemer et al., 2016; Anyanwu and Kolade, 2017). The low level of knowledge about ABS principles in the present study, further suggested that veterinary students in Nigeria may not be well exposed to the basic principles of ABS.

In this study, respondents shared common perceptions and attitudes about $\mathrm{AB}$ use/prescribing and resistance across the veterinary schools. Inappropriate $A B$ use may result from inadequate preparation at undergraduate level and an under-appreciation of the extent and implications of ABR (O’Donnell and Guarascio; 2017; Wasserman et al.,
2017). About two-third (65\%) of the respondents in this study perceived that $A B$ prescribing and use in most Nigerian veterinary hospitals are inappropriate. This finding is higher than 53.9\% reported by Anyanwu and Kolade (2017) among practicing/teaching veterinarians in Enugu State Nigeria, who also agreed that $\mathrm{AB}$ prescribing and use in most Nigerian veterinaryhospitals are inappropriate. But it is lower than $94 \%$ among 311 final-year students in 3 American medical schools (Abbo et al., 2013), 84.8\% among $6114^{\text {th }}$-year studentsin 3 Chinese medical schools (Yang et al., 2016) and 87.5\% among medical doctors/students in the Democratic Republic (DR) of Congo (Thriemer et al., 2013), respectively, who agreed that antimicrobials (AMs) are overused nationally in healthcare. It has been severally reported that $>50 \%$ of $A B$ prescription in hospital scould be adjudged inappropriate (Cotta $e t a l$., 2014; Cisneros et al., 2014); the case of veterinary hospitals in Nigeria may not be different as almost all the students in this study reported that antibiograms are rarely used during empiric treatmentin their institutional VTH where they have rotated and about half of the students do not know that treating self-limiting infections with $\mathrm{ABs}$ promotes ABR. It is disconcerting that despite the fact that all the participantsin this study agreed that ASP does not exist in anyveterinaryclinic/hospital in Nigeria, less than one-third (28\%) perceived that $\mathrm{ABs}$ areoverused in theirinstitutional VTH where they have rotated. Sixty nine percent among 579 graduating students in 12 American pharmacy schools (Justo et al., 2014) and 63\% among medical students in South Africa (Wasserman et al., 2017), respectively, perceived that AMs are overused in hospitals where they have rotated/are working.

The lower perception on $\mathrm{AB}$ overuse in local settings observed in this study, further suggested that NVS may not be well grounded on the issues of ABR and ABS, this is because arbitrary $\mathrm{AB}$ prescription not based on culture and sensitivity asobserved in the hereby study, is a major cause of ABR (Coyne et al., 2016; O'Donnell and Guarascio, 2017). It equally suggested that these students may also not be well grounded on how to detect cases associated with resistance in animals (Afzal Khan et al., 2013; O’Donnell and Guarascio, 2017). Many drivers are associated with overuse of drugs in Nigerian veterinary settings, including the use of $\mathrm{AB}$ to counterbalance poor hygiene, lack of knowledge/awareness about appropriate $\mathrm{AB}$ for specific infections, etc (Thriemer et al., 2013; Anyanwu and Kolade, 2017; O’Donnell and Guarascio, 2017). However, AB overuse could result from the intention to fulfill the responsibility of offering optimal therapy to the individual patient under a veterinary clinician's care while neglecting/overlooking the responsibility of preserving the efficacy of $\mathrm{AB}$ and minimizing the development of resistance in the same patient and other patients in the future and to public health (Scaiolietal., 2015; Gharbi et al, 2016; Anyanwu and Kolade, 2017).

Concerning theimpact and scope of ABR, majority of the respondents (74\%) in thisstudy believed that $A B R$ is a global problem, but there was significant variation $(P=$ $0.009)$ in responses between the schools. The global problem of ABR was perceived stronger (85.4\%-97.7\%) among medical/pharmacy students in other countries (Afzal Khanetal., 2013; Thriemer etal., 2013; Burger etal., 
166

2016; Padmanabha et al., 2016). It is a matter of serious concern that most students $(73 \%)$ in this study believed that $\mathrm{ABR}$ is not a significant problem in their institutional VTH where they have rotated whereas a minority of them $(9 \% ; P=0.030)$ felt that $\mathrm{ABR}$ is not a significant problem in Nigeria. These results suggested that NVS perceived AB overuse and resistance as beingof greater concern nationally than at theirlocal institutions. Medical/pharmacy students in other studies (Thriemer et al., 2013; Afzal Khan et al., 2013; Justo etal., 2014; Burger et al., 2016; Ferdoush et al., 2016; Padmanabha et al., 2016; Wasserman et al., 2017) similarly perceived $\mathrm{AB}$ overuse and resistance as being of greater concern nationallythan atlocal institutions; but in China, Yang et al. (2016) reported 15\% among medical students who believed that antimicrobial resistance (AMR) is not a significant problem in hospitals where they have rotated and $8.4 \%$ who perceived that AMR is not a significant problem nationally. Variations in perceptions of the impact and scope of the problem of $A B R$ in these studies may be related to the differences in exposure to the concept of ABR and/or level of knowledge about ABS possessed by the respondents in the various studies (Afzal Khan etal.,2013). The perceptions of NVS that ABR is of lesser problem in their institutional VTHs (local settings) may result in behaviours that are untoward ABS as Brink et al. (2017) rightly remarked "this view of 'not in my backyard' which suggests that others overprescribe ABs and drive resistance may contribute to inappropriate prescribing behaviour."

To effectively sustain behavioural change around $A B$ use/prescribing, an insight into, and an appreciation of, the factors leading to ABR is required (O'Donnell and Guarascio, 2017; Wassermanetal., 2017). The perception by most NVS that poor hand hygiene and poor infection control practices such as inadequate biosecurity and vaccination of animals against preventable diseases, are not important contributors to the spread of ABR, is very worrisome. Only $8 \%$ of participants in this study knew the importance of these practices in the spread of ABR. This finding is significantlylesser than the result (33.8\%-83.3\%) of previous studies (Afzal Khan et al., 2013; Burger et al., 2016; Ferdoush et al., 2016; Yang et al., 2016; W asserman et al., 2017) among medical/pharmacy students. Apart from improving farm biosecurity and routine animal vaccination against preventable diseases, improved personal hygiene, quarantine, herd testand isolation, are important infection control practices that can potentially reduce the use of $\mathrm{ABs}$ and hence development of ABR (Cotta et al., 2014; Llor and Bjerrum, 2014; Guardabassi and Prescott, 2015; Schwartz et al., 2016). The teaching of these practices in Nigerian veterinary schools should be endorsed and it should begin at early stages of veterinary education so that students would be able to practice them and educate their clients/the public how to curb ABR by these means, even before they qualify as veterinarians (Afzal Khan etal., 2013) Clear connection of $\mathrm{AB}$ prescribing in Pharmacology with infection control in Microbiology is crucial to enhance understanding of these practices by veterinary students (Afzal Khan et al., 2013).

Equally worrisome is that minority of students (15\%) in this study did not regard using substandard $\mathrm{AB}$ as a prominent cause of ABR Substandard drugs do not exert optimal therapeutic effect in animals thereby stimulating the development of ABR in both targeted and commensal bacteria (Garciaetal., 2011; Afzal Khan et al., 2013). The finding $(15 \%)$ of this survey islower than $48.8 \%$ and $71.2 \%$ reported by Burger et al. (2016) among pharmacy students in South Africa and Thriemer et al. (2013) among medical students in DR Congo, respectively. The use of substandard drugs is particularly important in Nigeria where there are no en forced regulations guiding the marketingand usage of $A B$ (Essack et al., 2017; Anyanwu and Kolade, 2017). The issue of substandard and counterfeit $\mathrm{AB}$ is associated with counterfeit/suboptimal activeingredient, poor production, shipping, storage and handling conditions (Essack et al., 2017). Maximization of profit, ignorance, client pressure, availability and affordability are enablers for consumption of substandard $A B$ in Nigerian veterinary settings (Guardabassi and Prescott, 2015; Anyanwu and Kolade, 2017).

The 3 leading potential drivers of $A B$ prescription identified by participants in this studywere: antibiogram of isolates $(52 \%)(P<0.001)$, health status of the patient (37\%) $(P=0.043)$ and cost of $\mathrm{AB}(37 \%)(P=0.002)$. This finding is troubling because only half of the students recognized the need for using antibiogram during prescription for empiric treatment of animals, which is a core strategy in ABS (O'Donnell and Guarascio, 2017). It is crucial that NVS are exposed to methods utilized in rapid identification and susceptibility testingof bacteria(Okeke $e t$ al., 2011; Maurer et al., 2017). Although in the minority $(11 \%)$ in thisstudy, reliance on senior colleagues to make AM prescribing decisions has been identified as a barrier to appropriate $\mathrm{AB}$ prescribing (Chaveset al., 2014). Thriemer et al. (2013) reported $79.4 \%$ among medical studentsin DR Congo who agreed they sometimes consult senior colleagues on $\mathrm{AB}$ prescribing. Less than $10 \%$ of NVS reported that their peers (otherstudents) could have influence on their decision to prescribe an $\mathrm{AB}$.

Although in the minority, it is concerning that client pressure/push (18\%) $(P=0.020)$ and profit to be made $(15 \%)$, were mentioned as factors that could influence $A B$ prescription by NVS. In previous surveys among practicing medical doctors (Garcia et al., 2011; Abera et al., 2014; Shanuga Vadivoo et al., 2015), patient push/demand, patient's health statusand profit of hospitals were perceived even stronger as thriving factors/drivers for unnecessary $A B$ prescribing. The high expectation of $A B$ use by clients is often a consequence of their lack of knowledge about these drugs and their side effects; therefore, veterinary students should be well educated and knowledgeable about these concepts in order to take the leading role as educators of their clients/the public (Garciaet al., 2011; Bowater,2015). Good enough, although with significant difference in responses between the schools, a vast majority $(84 \%, P=$ 0.047 ) of NVS agreed that inappropriate use of AB can directly harm patient (O'Donnel and Guarascio, 2017). This finding is consistent with that of previous studies (Abbo et al., 2013; Justo et al., 2014; Burger et al., 2016; Ferdoush etal., 2016; Padmanabha et al., 2016; Yang et al., 2016; Wasserman et al., 2017) among medical/pharmacy students in other countries. It is however unfortunate that 
less than half (41\%) of the students in this study, were confident that they can handle clients demanding unnecessary $A B$ therapy for their animals. In Bangladesh (Ferdoush et al., 2016), China (Yang et al., 2016) and America (Abbo et al., 2013), 13\%, 25.6\% and 54\% among medical students, respectively, were confident they can handle patients demanding unnecessary $A B$ therapy. However, prescribing decision of a veterinarian is made after consideration of intrinsic and extrinsic factors (such as type of husbandry practice in food-producing animals) (Coyne et al., 2014; Speksnijder et al., 2015). A sense of responsibility should be nutured in NVS, that as prescribers, they are not only responsiblefor the benefit/welfare of their patients and satisfaction of their clients, but also for the society at large (Afzal Khanetal.,2013). These skills should be targeted in future $\mathrm{ABS}$ educational interventions in Nigerian veterinary schools. Teaching of the principles of protocol development in VTHs and small group exercises facilitating client education skills (such as educating clients about the need and proper use of $A B$ in animals), should form an integral part of the veterinary undergraduate studies (Steiner $e$ t al., 2004; Afzal Khan etal., 2013). The findings in this survey showed that there is need for urgent intervention by ABS education in NVS in order to change perceptions and attitude of these future veterinarians regarding $A B$ use. Apart from improving knowledge, a key objective of ABS education is to shift attitudes, perceptions and prescribing behaviours (Ohl and Luther, 2014; Wasserman et al., 2017).

The 3 leading causes of $A B R$ identified in this study were: widespread/overuse of $A B$ in humans and animals (55\%), use/prescription of $\mathrm{AB}$ by nonveterinarians/professionals (29\%) and unnecessary use of broad-spectrum $\mathrm{AB}$ for treating animals when narrowerspectrum antibiotic is available (26\%). Pharmacy students in South Africa (Burger et al., 2016) and practicing physicians in other countries (Pulcini et al., 2011; San Fransisco et al.,2013; Abera etal.,2014), also observed these 3 factors and others, as leading causes of ABR. The 26\% respondents in thisstudy who agreed that unnecessary use of broad-spectrum $\mathrm{AB}$ promotes $\mathrm{ABR}$, is lower than the result (32.5\%-95\%) of previousstudies (Abbo et al., 2013; Justo etal., 2014; Burger et al., 2016; Ferdoush et al., 2016; Yang et al., 2016; Wasserman et al., 2017) among medical/pharmacy students. Administration of inappropriate doses of $\mathrm{AB}$ for inadequate frequency was perceived by less than one-third (29\%) of respondents in this study as cause of ABR; this attitude/factor was perceived stronger (30.9\%-90\%) as a cause of ABR by medical/pharmacy students in other studies (Thriemer $e t$ al., 2013; Burger et al., 2016; Weier et al., 2017). But a weaker perception (27.54\%) of this attitude as a cause of $\mathrm{ABR}$ was observed among $1622^{\text {nd }}$-yearmedical students in India (Padmanabha et al., 2016). In future educational interventions in Nigerian veterinary schools, emphasis should be placed on teaching $\mathrm{ABS}$ which involves avoiding selection pressure in the patient, both on the pathogen and commensal by avoiding unnecessary use, choosing the least broad-spectrum $\mathrm{AB}$, adequatedoses, a good timing and the shortest possible duration (Pulcini and Gyssens, 2013; Ohl and Luther, 2014; Nori et al., 2017).
It calls for serious concern that most NVS do not know that Staphylococcusaureus (39\%), Pseudomonas aeruginosa (17\%) and Clostridium difficile (13\%), Enterococcus faecium (4\%) and Klebsiella pneumoniae (6\%), are troublesome zoonotic antibiotic-resistant bacteria of global public health concern (WHO, 2017). Burger et al. (2016) reported that 45\%-81.9\% (range for the pathogens) among final year pharmacy students in South Africa, knew that these resistant bacteria are of zoonotic and public health importance. The knowledgegaps observed in this study on zoonotic troublesome pathogens, suggested that there is unavailability and/or lack of bacteriological culture and sensitivity testing in most (if not all) the VTHs in Nigeria (Pulcini et al., 2011; Abera et al., 2014). It also suggested that there may be need for the Microbiology curricula of veterinary schools in Nigeria to be improved, especially on the issues of medically-important pathogens and ABR with these topics taught from a 'One Health' perspective (O’Donnell and Guarascio, 2017).

Regarding interventions to combat $\mathrm{ABR}$, majority of students $(78 \%)$ in this survey agreed that better use of $A B$ will reduce problems with $A B R$, but medical/pharmacy students (86.1\%-98.5\%) in other countries (Abbo et al., 2013; Justo et al., 2014; Burger et al., 2016; Wasserman et al., 2017) were better convinced that this attitude will help to contain ABR. Encouragingly, most NVS recognized that establishment and implementation of ASPs in veterinary hospitals in Nigeria are essential to ensure better use of $A B$. The findings that most studentsin this study do not know that education on $\mathrm{AB}$ therapy (44\%), development of antibioticusage policies (35\%), reduction of $A B$ use (14\%), establishment of national $\mathrm{AB}$ resistance surveillance (28\%) and development of institutional guidelines for antibiotic use (29\%), are critical interventions to curb ABR (Schwartz et al., 2016) is very worrisome. These results arelower than 65.8\%-92.3\% (range for all the interventions) recorded by Burger et al. (2016) among pharmacy students in South Africa. The poor knowledge exhibited by students in this current survey suggested that veterinary students in Nigeria have poor knowledge about $\mathrm{ABS}$ interventions to contain ABR The misperception by majority of NVS (71\%) that new $A B$ will be developed in the future to keep up with the problem of ABR calls for concern. Medical students in China (Yang et al., 2016) had a stronger misperception (76.9\%) that new $\mathrm{AB}$ will be developed in the future to keep up with the problem of $A B R$ whereas medical/pharmacy students elsewhere (Abbo et al., 2013; Justo et al., 2014; Wasserman et al., 2017) had a better perception/understanding (15\%-27\%) in terms of difficulties associated with the development/manufacturing of new $\mathrm{AB}$ in the future (Theuretzbacher et al., 2017).

The general goal of $A B S$ is to ensure appropriate use of $A B s$, this entailscosteffective use of $A B$ which maximizes therapeutic effect while minimizing both drug related toxicity and ABR (WHO, 2011; Oberje et al., 2017). Among the goals of ABS asked in this survey, it is only increasing the use of $\mathrm{AB}$ that was rightly perceived by all the respondents not to be a goal of ABS. Nevertheless, it gives concern that minority of students in this study knew that reducing hospital stay (2\%), reducing $\mathrm{ABR}(17 \%)$ and minimizing toxicity and other adverse effects $(6 \%)$ are goals 
168

of ABS (WHO, 2011). These results are lower than the findings (72.5\%-98.5\%) of Burger et al. (2016) among pharmacy students in South Africa. This further suggested that respondentsin this study have poor knowledge about the concept of ABS. It is also of concern that although in the minority, some students in this survey thought that increasing the use of broad-spectrum $A B s(1 \%)$ and increasing the duration of therapy to ensure therapeutic success (2\%), were also among the goals of ABS. In South Africa, Burger et al. (2016) reported $7.7 \%$ and $10.4 \%$ among pharmacy students, who thought that $\mathrm{ABS}$ seek to increase the use of broad-spectrum $A B$ s and increase the duration of therapy to ensure therapeutic success, respectively. Poor knowledge about goals of $A B S$ exhibited by respondents in this study may be attributed to lack of awareness/exposure to the basic concepts of $A B S$ in the veterinary schools. It is imperative that these veterinary students understand that the goal of $A B S$ is notonly to reduce total $A B$ use but also to ensure that $A B$ s are prescribed only when indicated, at the correct dose, route, and for proper duration for each infection (Ohl and Luther, 2014; Nori et al., 2017).

It is unfortunate that less than $20 \%$ of students in this study knew that veterinarians are responsible for leading $\mathrm{ABS}$ team especially in veterinary settings (Brink et al., 2017; Espinosa-Gongora et al., 2017) and also a vast majority of them do not know the members to constitute an ABS team (MacDougall and Polk, 2005). ABS is a team effort that must involve the whole continuum of heal thcare workers (Pereira et al., 2017). Veterinarians (19\%), Veterinary hospital cleaning staffs (13\%) and Veterinary pharmacists (13\%), were the members of ABS team mostly identified in this study whereas Veterinary clinical microbiologist and Veterinary assistants were the least mentioned (5\%). However, there was significant variation $(P<0.001)$ in responses between the schools regarding hospital cleaning staffs being members of ABS team. Final year pharmacy students in South Africa exhibited higher level of knowledge(range for listed members, 20.8\%-95\%) about members of an ABS team (Burger et al., 2016). The professionals, including veterinarians, have the responsibility of formingABS team and developing effective ASPs in their settings (MacDougall and Polk, 2005; Brink et al., 2017). Veterinarians are prescribers and in private veterinary clinics in Nigeria, they also double as dispensers; thus, serving as the 'nucleus' of ABS team in veterinary settings (Khan et al., 2017).Veterinarians play a crucial role in the surveillance of and feedback on $A B S$ practices as they prescribe and dispense AB (Fairles, 2013; Khan et al., 2017). The role of Veterinary clinical microbiologist in ASPs is critical because laboratory diagnosis (isolation and identification of bacteria) and conduct of $A B$ sensitivity, is the only way to avoid blind $A B$ prescription and therapy and hence unnecessary use (overuse) of ABs (MacDougall and Polk, 2005; O'Donnell and Guarascio, 2017). Collaboration with Microbiology laboratory is a major requirement for ASP and to achieve ABS (Coyne et al., 2016; Gharbi et al, 2016). ABS education intervention in Nigerian veterinary schools should emphasize the importance of a multidisciplinary $\mathrm{ABS}$ team in which veterinarians and other professionals combine to achieve the 'One Health' goals (O'Donnell and Guarascio, 2017). The poor knowledge exhibited by NVS about ABS team formation, further suggested the need for integration of $\mathrm{ABS}$ education in to the curricula of veterinary schools in Nigeria. These students need to understand their role (and that of other healthcare workers) as future leaders (steward champions) in the fight against ABR (Espinosa-Gongora et al., 2017; MacDougalletal.,2017; Wasserman etal., 2017).

Concerning the roles of veterinarians in ASPs, more than one-third of students (69\%) in this study thought that prescribing $A B$ over-the counter is the major role of veterinariansin ASPs whereas a minimal number perceived that promoting the optimal use of $\mathrm{AB}(15 \%)$, educating veterinary allied healthcare professionals (13\%) and working with therapeutic committees to develop policies (7\%), were the minor roles of veterinarians in ASPs. This further suggested that these students possessed abysmal knowledge about their roles (as future veterinarians) in ensuring appropriate use of $\mathrm{AB}$. A higher level of knowledge (7.3\% for prescribing over-the-counter and $88.5 \%-92.3 \%$ for the other roles) was exhibited by final year pharmacy students in South Africa regarding their roles (as future pharmacists) in ASPs (Burger et al., 2016). Differences in exposure to $\mathrm{ABS}$ education may account for the variations in perceptions among the students in the various studies.

The availability of unbiased information about $A B$ is a prerequisite for appropriate $\mathrm{AB}$ prescribing (Threimer $\mathrm{et}$ al., 2013; WHO, 2012). In this survey, although in the minority, more students (36\%) referred to iPhone/Smart phone applications and lecturers/resident doctors $(25 \%)$ than textbooks $(17 \%)$ or formally peer-reviewed sources of information, including the Nigerian veterinary formulary (14\%), Merck's/Black's veterinary manual (17\%) and medical/veterinary journals (12\%), and very minor proportion of respondents in this study referred to Wikipedia (8\%), Veterinary hospital pharmacists (3\%) and Veterinaryassistants (2\%). In previous multicentre studies (Minen et al., 2010; Abbo et al., 2013; Justo et al., 2014; Ferdoush et al., 2016; Yang et al., 2016) among medical/pharmacy students, significantly higher proportion of students referred to iPhone/Smart phone applications (50.5\%-72\%), textbooks (46\%-80.2\%), Wikipedia (36\%$52.1 \%)$ and medical/veterinary journals (19.7\%-82\%), respectively. Unlike these previous multicentre studies among medical/pharmacystudents, this present survey did not assess whether there was association between knowledge scores and the sources of educational information. However, some studies (Minen et al., 2010; Justo et al., 2014) showed that students who referred to peer-reviewed sources of information performed significantly higher in knowledge questions than those who referred to non-peerreviewed sources such as Wikipedia. Nevertheless, the differences in knowledge was not actually attributed to the educational resources utilized but rather to several other reasons, including, personal experiences, motivations, availability of educational resources, instructional initiatives, influence of senior colleagues during clinical trainings and teaching methodology at each site (Minen et al., 2010; Justo et al., 2014). In any case, NVS should be encouraged to refer to peer-reviewed resources for information about $A B$ use and resistance because these materials contain more reliable and accurate information than the non-peer reviewed 
resources (Minen et al., 2010). A balanced approach in the utilization of peer reviewed and non-peered reviewed resources like Wikipediahas been suggested (Minen $e t$ al., 2010). Economic constraint on the part of the students and limited internet access in Nigeria, are factors that may limit access of NVS to internet-based educational resources (Thriemeret al., 2013). As such, interactive classic face-toface trainings may be more effective and feasible than elearning tools in future $\mathrm{ABS}$ interventions in Nigerian veterinary schools (Afzal Khanetal.,2013; Threimer et al., 2013).

The use oflocal prescribing guidelines (in this case the Nigerian veterinary formulary) should be promoted (Chaves et al., 2014; Wasserman et al., 2017). Medical practitioners elsewhere rated local guidelines on AMs and AM prescribing better than international guidelines (Garcia et al., 2011; Chaves et al., 2014) and medical students in South Africa who referred to local prescribing guidelines, exhibited higher knowledge scores and better confidence in $\mathrm{AB}$ prescribing (Wasserman et al., 2017). Information provided by pharmaceutical industries and the WHO (Threimeretal.,2013) arealso important resources whose usefulness to veterinary students' education on $A B$ use and resistance, may be assessed in future studies.

Very few (5\%) of the students in this survey indicated that theyconsulted their peers on $\mathrm{AB}$ use and resistance. Previous studies (Minen et al., 2010; Abbo et al., 2013; Justo et al., 2014; Ferdoush et al., 2016; Yang et al., 2016) among medical/pharmacystudents, reported a significantly higher proportion of students $(25.474 \%)$, who agreed that they consulted their colleagues on $A B$ prescribing. Lack of self-confidence has been suggested as causes why health profession students do want the inputs of their colleagues during $\mathrm{AB}$ use/prescribing (Thriemer et al., 2013). Therefore, thelower propensity of studen ts to consult peers observed in this study, might be related to the fact that very few participantsin this surveyhave prescribed or have been allowed to prescribe ABs in their institutionalVTHs; thus, most NVS have not faced challenges in which the need for consul ting their peers arise. Interaction of undergraduates with lecturers/resident doctors (learning resource) was reported in this study but with significant variation $(P=$ $0.014)$ in responses between the schools. Studentlecturer/resident doctors' interaction usually takes place during classlectures/clinical rotations in VTHs; therefore, it could be considered an active form of teaching/learning (Wasserman et al., 2017). The levels of competence of the lecturer(s)/resident doctor(s) about $\mathrm{ABS}$, degree of engagement with undergraduate students and the content and design of these interactions, will determine the effect of these human resources on the knowledge and modification of behaviour of veterinary students regarding $A B$ use (Pulcini and Gyssens, 2013; Wasserman et al., 2017). In medical settings, prescribing advice from a multidisciplinary management team resulted in more appropriate $A B$ prescribing than in put from residents alone (Gross et al., 2001; Wasserman et al., 2017). Thus, in future ABS education interventionsin NVS, emphasis should be laid on multidisciplinary approach to $\mathrm{AB}$ prescribing (Friedman et al., 2016; Schellack et al., 2016; Roca et al., 2015; Wasserman et al.,2017). Class lecture noteswas referred to by $16 \%(P=0.010)$ of students in this study; this highlights the potential role of classlectures in veterinary schools as a forum for interventions on ABS (Thriemer et al., 2015). These veterinary students who are the future lecturers should therefore be well educated and equipped about issues of ABR and ABS (MacDougall et al., 2017; Weier et al., 2017).

Less than $20 \%$ of students in this survey believed that their education on specific ABS activities was good and useful. Majority of NVS had a comfortable understanding of basic mechanisms of $A B R$, selecting the best $A B$ for specific infection, spectra of therapy for different $\mathrm{AB}(P=$ 0.020 ), and less than two-third of them felt comfortable with when to start $A B$ therapy, findingreliableinformation to treat patients and interpretation of antibiograms. The students exhibited suboptimal knowledge and preparedness regarding transitioning from intravenous to oral $\mathrm{AB}$, and performance of de-escalation. These findings further suggested that there are deficiencies in Microbiology and Pharmacology training at undergraduate level in Nigerian veterinary schools (Afzal Khan et al., 2013; O’Donnell and Guarascio, 2017; Wasserman etal., 2017). Moreover, most of the students $(88 \%)$ havenever had any formal training on ABS, with the only knowledge they had on stewardship being from class lectures. In addition, the minor proportion of NVS who reported to have had a formal lecture on ABS did so within a short duration which may not have been enough to have a good grasp/understanding of these ABS skills. The gap in stewardship knowledge observed in this study suggested that there is need for more clinic practical training than class lectures in Nigerian veterinary schools (Yang et al., 2016). This study did not assess various teaching modalities that could be employed in delivering ABS trainings to NVS. However, passive education such as class lectures hasbeen reported to have limited impact on improving $\mathrm{AB}$ use on its own (Pulcini and Gyssens, 2013; Ohl and Luther, 2014; Wasserman et al., 2017); however, it is an important method to teach fundamental stewardship principles (Khan et al., 2017; Wasserman et al., 2017). In South Africa, medical students rated the usefulness of formal lecturesin $\mathrm{AB}$ prescribing very low (Wasserman $e t$ al., 2017). It has been reported that there is often a failure in translating classroom knowledge into clinical prescribing practice, and there is discordance between knowledge and practice (Eyal and Cohen, 2006; Scaioli et al., 2015; Wasserman et al., 2017). More active educational approaches such as clinical case discussions and interactive elearning are generally considered to be more effective for influencing prescribing behaviours (Ohl and Luther, 2014; Broom et al., 2016; Wasserman et al., 2017).

Two key stewardship concepts that were mostly misunderstood by NVS are transitioning from intravenous to oral $A B(27 \%)$ and de-escalation of $A B$ therapy (19\%). These concepts/strategies are utilized internationally (Shrahtey et al. 2015; Broom et al., 2016; O'Donnell and Guarascio, 2017) and every veterinary undergraduate should be knowledgeable about them for obvious reasons: early switch from intravenous to oral $\mathrm{AB}$ reduces duration of $\mathrm{AB}$ therapy, length of hospital stay, intravenousassociated morbidity and improve costeffectiveness (Broom et al., 2016). De-escalation is a critical strategy in reducing 
170

overuse of broad-spectrum $A B$, in practice, it entails daily review of broad-spectrum prescriptions (where it is imperative to use broad-spectrum therapy) and deescalation to narrow-spectrum where possible (Abbo et al., 2013; Roca et al. 2015; Wickens et al., 2013). Medical/pharmacy students in other countries (Abbo et al., 2013; Justo et al., 2014; Ferdoush etal., 2016; Haque et al., 2016; Yang et al., 2016) were more confident with their education (32\%-51\% and $25.6 \%-54 \%$, respectively) than NVS (27\% and 19\%, respectively) on transitioning and deescalation, respectively, but NVS felt more confident on transitioning than medical students (18\%) in Bangladesh (Ferdoush et al., 2016). Regarding basic mechanisms of $\mathrm{ABR}$, selecting $\mathrm{AB}$ and interpreting antibiograms, NVS felt more comfortable $(74 \%, 79 \%$ and $60 \%$, respectively) than medical/pharmacy students elsewhere (54.1\%-59\%,36.9\%67\% and 35.2\%-59\%, respectively) (Abbo et al., 2013; Justo et al., 2014; Haque et al., 2016; Yang et al., 2016). The differencesin these responses may be due to variation in the method of teaching in the schools, extent of trainings the students have received on those topics, individual experiences, and differences in knowledge about stewardship skills acquired by individuals from other means/sources and/or degree of casual answers that were correct. This survey did not evaluate the usefulness of modalities that could be employed in Nigerian veterinary schools todeliver trainings on $\mathrm{ABR} / \mathrm{ABS}$ to the students.

Gaps in knowledge about $A B$ were identified among veterinary studentsat all the study sites, without significant differences $(P>0.05)$ between the 5 schoolsinall the areas. Majority of the students did not know the appropriate management of complicated urinary tract infection in companion animals (19\%) (Wesse et al., 2011) and ESBLresistant infections in companion animals (11\%) (Spohr $e t$ al., 2012), recognition of critically-important $A B$ for human use (9\%) (WHO, 2016) and Clostridium difficile infection (25\%) (Keesen et al., 2011) and determination of antibiogram of colistin-resistant enterobacterial isolates (2\%) (Nordmannetal., 2017), only about one-third of the respondents appropriately recognized risks associated with unnecessary use of $\mathrm{AB}$ in animals (62\%) (Llor and Bjerrum, 2014) and scenarioswith potential for unnecessary use of $\mathrm{AB}$ in animals (Llor and Bjerrum,2014), and slightly above half $(56 \%)$ appropriately recognized the spectrum of activity of certain selected AB (Coates et al., 2011). Students in this study performed sub-optimally in matching specific bacteria/AB and resistance mechanism. This finding creates a doubt regarding the report by majority of them that their education about selecting the best $\mathrm{AB}$ for specific infection and basic mechanism of $A B R$ was good. It is crucial that veterinary studentsunderstand the concept of the 'bug drug' coverage, where the selection of appropriate $\mathrm{AB}$ therapy is selected based on the likely pathogens involved in a given condition (O'Donnell and Guarascio, 2017).

In this survey, the overall knowledge score was $29 \%$ which is considered poor with similar scores across the schools. This finding suggested that NVS have low level of knowledge about the clinical vignettes and thus may be inadequatelyprepared to practice ABS (Brink et al., 2017; O'Donnell and Guarascio, 2017; MacDougall et al., 2017). The finding further suggested that however well-meaning, stewardship-related diagnostic or therapeutic teaching, lectures, does not translate into clinical practice (Brink et al, 2017). This present survey did not assess whether there was an association between the respondents' knowledge scores and their perceptions about the quality of their AB-related education. Moreover, evaluation of the formal curricula of veterinary schools regarding education about $\mathrm{ABs}$ is not the focus of this study. However, the respondents' perception and clinical vignette knowledge scoresfurther suggested that there are deficiencies in the Nigerian veterinary schools' curricula, including fundamental concepts of $\mathrm{AB}$ use (Abbo et al., 2013). These deficiencies could be addressed by standardization of Nigerian veterinary schools' curricula about $\mathrm{AB}$ use and resistance, providing easy access to accurate information and emphasizing the importance of clinical rotationsin the VTHs (Abbo et al., 2013; Brink et al., 2017). The use of standardized educational electronic tools with clinical scenarios has been recognized as effective means of improving $A B$ use in undergraduate veterinarians (Pulcini et al., 2011; Abbo et al., 2013).

Most students (88\%) in this survey agreed that strong knowledge of $\mathrm{AB}$ is important for their future veterinary career but the proportion is lower than that (91.8\%-98.5\%) of previous studies (Abbo et al., 2013; Justo et al., 2014; Burger et al., 2016; Ferdoush et al., 2016; Yang et al., 2016; Wasserman et al., 2017) among medical/pharmacy students. This finding showed that NVS had a lower understanding about the potential impact of $\mathrm{ABR}$ on their future career than the studentsin the previous surveys; this could be attributed to inadequate understanding of the implications of ABR by NVS. Low level of awareness/knowledge about $\mathrm{ABR}$ and $\mathrm{ABS}$ in the various institutions and/or study area may account for the differences in the perceptions of impact of $A B R$ on future career. In this study, students recognized theimportance of appropriate $\mathrm{AB}$ use and majority indicated they would like more education on ABR (73\%) and ABS (87\%). This receptive attitude to $A B S$ education by NVS is consistent with the findings of previous studies (Abbo et al., 2013; Burger et al., 2016; Yang et al., 2016; Wasserman et al., 2017). Majority of NVS opined that ABS education should occur at all levels in the veterinary school. By taking advantage of the receptive view of these students to improve their knowledge about $A B R$ and $A B S$, the Veterinary Council of Nigeria, veterinarians in the academic setting and other stakeholders, should consider forming an expert group comprising of competent individuals from VM, Veterinary Public Health, Veterinary Microbiology and Pharmacology, who would assess the curricula of veterinary schools with the intention of developing a standardized, structured and practical ABR and ABS curricula (Brink et al., 2017; Espinosa-Gongora et al., 2017; Khan et al., 2017). This would address the disparate education that Nigerian VM undergraduates are receiving (Brink et al., 2017).

It has been suggested that $A B S$ should be taught concurrently with foundational learning of bacteria and $A B$ rather than waiting until habits are already established at later stages of the veterinarian's career (Schwartz et al., 2017). Changing behaviouris a lot harder than shaping it and once veterinarians become qualified and gained experience, their viewsand behaviours become very hard to 
change (Lee et al., 2015; Pereira et al., 2017; Nori et al., 2017). In medical settings, students in previous surveys suggested that education on $\mathrm{AB}$ should occur at a later stage/level of theireducation (Abboetal., 2013; Ferdoush et al.,2016). But the qualificationsfor entry into these health profession institutions vary in different countries, and this should be considered if the need for modification of the curricula of veterinary schools in Nigeria arises; this is because most students are admitted into Nigerian veterinary schools with basic secondary school qualifications. There may also be need for integration of an inter-professional $\mathrm{ABS}$ education in the curricula of Nigerian universities; this may help in exposing students to the concepts of ABS from the early stages of their university education (Schellack et al., 2016; MacDougall etal., 2017; Pereira et al.,2017; Shwartz and Chin-Hong, 2017). Early education integrates stewardship into students' core understanding of ABS principles and this will likely lead to long term incorporation of these principles into future $\mathrm{AB}$ use/prescribingpractices (Brinketal., 2017; Schwartz et al., 2017).

Strengths of this study were that it highlighted an area where there is little or no availability of literature. A relatively high response rate (53.4\%) compared with previous multicentre surveys in medical/pharmacy settings (51\% (Wasserman et al., 2017), 61\% (Abbo et al., 2013), 26.6\% (Burger et al., 2016),30\% (Minen et al., 2010), 35\% (Dyar etal., 2014), 40\% (Justo et al., 2014), 82\% (Ferdoush et al.,2016)) was obtained and the survey was anonymous and voluntary; this likely reduced the tendency of the students to produce "socially desirable" response (Abbo et al., 2013; Thriemer et al., 2013; Burger et al., 2016). The study was conducted in the final-year of veterinary undergraduatestudy when students havealmostcompleted their formal academic curriculum, thus providing a good estimate of their education about ABR and ABS upon graduation (Abboetal., 2013; Burger et al., 2016). All the participants responded to all the survey questions so there was no need for adjusting using the series means (Abbo et al., 2013; Yang et al., 2016). The external validity of this study is supported by the fairly consistent responses between the veterinary schools in this survey, and those from multicentrestudies (Minen et al., 2010; Abbo et al., 2013; Justo etal., 2014; Burger et al., 2016; Ferdoush et al., 2016; Yang et al., 2016) in non-veterinary settings from other countries. This survey addressed most of the topic cited by WHO as influencing $\mathrm{AB}$, development of $\mathrm{ABR}$ and $A B S$ strategies to contain escalating $A B R$ from a 'One Health' approach (Thriemer et al., 2013; WHO, 2012). Because of the inclusion of 5 diverse and geographically distant veterinary schools (although 2 were in the same geopolitical region), the findings of this study are likely to be generalizable to other Nigerian veterinary schools. Any difference in responses or knowledge scores may be related to difference in pedagogies which was not assessed.

Potential for recall biasis possible sinceall measures were based on self-report (Abbo et al., 2013; Ferdoush et al., 2016). However because only final-year students were surveyed in the 5 sites, it is likely that the respondents and non-respondents had similardemographic characteristics, perhaps minimizing the selection bias (Johnson and Wislar,
2012; Abbo et al., 2013). Nonetheless, the relatively low response rate in some of the veterinaryschools in this study may imply that interpretation of the results should be done with caution.

\section{Conclusions}

In conclusion, the final-year VMSin Nigeria have poor knowledge/awareness about ABR and ABS; thus they may not be adequately prepared to practice $\mathrm{ABS}$. Intervention by ABS education in Nigerian veterinary schools are urgently needed. NVS desired so much to be more educated about $A B R$ and ABS. Despite the identified limitations, the findings of this study could be useful in improving the undergraduate curricula of Nigerian veterinary medical schools in order to produce veterinarians who are adequately knowledgeable about $\mathrm{AB}$ and $\mathrm{ABR}$, and can confidently stand on the frontline of the fight against ABR.

\section{Acknowledgements}

This research received no specific grant from any funding agencyin the public,commercial, or not-for-profit sectors.

\section{References}

Abbo LM, Cosgrove SE, Pottinger PS, Pereyra M, Sinkowitz-Cochran R, Srinivasan A, ... Hooton TM (2013). Medical student's perceptions and knowledge about antimicrobial stewardship: How are we educating our future prescribers? Clinical Infectious Diseases 57(5):631-638.

Abera B, KibretM, Mulu W (2014). Knowledge and beliefs on antimicrobial resistance among physicians and nuses in hospitals in Amhara Region, Ethiopia. BMCPharmacology and Toxicology 15:26.

Afzal Khan $A K$, Banu G, Rehma KK (2013). Antibiotic resistance and usage- a survey on the knowledge, attitude, perceptions and practices among the medical students of a southern Indian teaching hospital. Journal of Clinical Diagnostic Research 7:1613-1616.

Anyanwu MU, Kolade OA (2017). Veterinarians' perception, knowledge and practices of antibiotic stewardship in Enugu State Southeast, Nigeria. Notulae Scientia Biologicae 9(3):321-331.

Beerlage-De Jong N, Gemert-Pïnen L, Wentzel J, Hendrix R, Siemons L (2017). Technology to support integrated antimicrobial stewardship programs: a user centred and stakeholder riven development approach. Infectious Disease Reports 9:6829.

Bowater L (2015). Antimicrobial stewardship: the role of scientists? Journal of Antimicrobial Chemotherapy 70:1925-1927.

Brink A, Shoeman J, Muntingh G (2017). Undergraduate antibiotic stewardship training are we leaving our future prescribers flapping in wind? South African Medical Joumal 107(5):357-358.

Broom J, Broom A, Adams K, Plage S (2016). What prevents the intravenous to oral antibiotic switch? A qualitative study of hospital doctors' accounts of what influences their dinical practice. Journal of Antimicrobial Chemotherapy 71:2295-2299.

Burger M, Fouriea J, Lootsa D, Mnisia T, Schellacka N, Bezuidenhouta S, Meyera JC (2016). Knowledge and perceptions of antimicrobial stewardship concepts among final year pharmacy students in pharmacy schools across South Africa. South African Journal of Infectious Diseases 31(3):8490. 
172

Castro-Sánchez E, Drumright LN, Gharbi M, Farrell S, Holmes AH (2016). Mapping antimicrobial stewardship in undergraduate medical, dental, pharmacy, nursing and veterinary education in the United Kingdom. PLoS ONE 11:doi:10.1371 /journal.pone.0150056.

Chaves NJ, Cheng AC, Runnegar N, Kirschner J, Lee T, Buising K (2014). Analysis of knowledge and attitude surveys to identify barriers and enablers of appropriate antimicrobial prescribing in three Australian tertiary hospitals. Internal Medicine Joumal 44:568-574.

Cisneros JM, Neth O, Gil-Navarro MV, Lepe JA, Jimenez-Parrilla F, Cordero E, ...PRIOAM Team (2014). Global impact of an educational antimicrobial stewardship programme on prescribing practice in a tertiary hospital centre. Clinical Microbiology and Infection 20(1):8288.

Coates ARM, Halls G, Hu Y (2011). Novel classes of antibiotics or more of the same? British Journal of Pharmacology 163:184194.

Cotta MO, Robertson MS, Tacey M, Marshall C, Thursky KA, Liew D (2014). Attitudes towards antimicrobial stewardship: results from a large private hospital in Australia. Healthcare Infection 19(3):89-94.

Coyne LA, Latham SM, Williams NJ, Dawson S, Donald IJ, Pearson RB, Smith RF, Pinchbeck GL (2016). Understanding the culture of antimicrobial prescribing in agiculture: a qualitative study of UK pig veterinary surgeons. Journal of Antimicrobial Chemotherapy 71:33003312

Dellit TH, Owens RC, Mcgowan JE Jr, Gerding DN, Weinstein RA, Burke JP, ... Hooton TM, Infectious Diseases Society Of America, Society For Healthcare Epidemiology Of America (2007). Infectious Diseases Society of America and the Society for Healthcare Epidemiology of America guidelines for developing an institutional program to enhance antimicrobial stewardship. Clinical Infectious Diseases 44(2):159-177.

Dyar OJ, Hills H, Seizz LT, Perry A, Ashiru-Oredope D (2018). Assessing the knowledge, attitudes and behavior of human and animal health students towards antibiotic use and resistance: a pilot cross-sectional study in the UK. Antibiotics 7(10) doi:10.3390/antibiotics7010010.

Dyar OJ, Pulcini C, Howard P, Nathwani D, ESGAP (ESCMID Study Group for Antibiotic Policies) (2014). European medical students: a first multicentre study of knowledge, attitudes and perceptions of antibiotic prescribing and antibiotic resistance.Journal of Antimicrobial Chemotherapy 69:842-846.

Espinosa-Gongora C, Dyar O, Beovic B, Bousquet-Melou A, GonzalezZom B, Jessen LR, ... Guardabassi L (2017). Towards a comprehensive education and training of European veterinary students in antimicrobial stewardship. 27 $7^{\text {th }}$ ECCMID Congress Vienna 2017.

Essack SY, Desta AT, AbostsiRE AgobaEE (2017). Antimicrobial resistance in the WHO African region: current status and roadmap for action. Journal of Public Health 39(1):8-13.

Eyal L, Cohen R (2006). Preparation for clinical practice: A survey of medical students' and graduates' perceptions of the effectiveness of their medical school curriculum. Medical Teacher 28:e162-e170.

Fairles J (2013). The veterinarian's role in antimicrobial stewardship. Canadian Veterinary Journal 54(3):207-210.

Ferdoush J, Ata M, Parveen K, Reza FH, Rahman MS (2016). Knowledge, perception and preparedness of future prescribers about antimicrobial stewardship. Bangladesh Journal of Pharmacology 11(4):928-934.

Fitchett JR, Atun R (2016). Antimicrobial resistance: Opportunity for
Europe to establish global leadership. Lancet Infectious Diseases 16:388389.

Friedman ND, Temkin E, Carmeli Y (2016). The negative impact of antibiotic resistance. Clinical Microbiology and Infection 22(5): 416 422.

Garcia C, Llamoca LP, Garcia K, Jimenez A, Samalvides F, Gotrzzo E, Jacobs J (2011). Knowledge, attitudes and practice survey about antimicrobial resistance and prescribing among physicians in hospital setting in Lima Peru. BMC Clinical Pharmacology 11:8.

Gharbi M, Moore LSP, Castro-Sánchez E, Spanoudaki E, Grady C, Holmes AH, Drumright L (2016). A needs assessment study for optimising prescribing practice in secondary care junior doctors: the antibiotic prescribing education among doctors (APED). BMC Infectious Diseases 16:456.

Gross R, Morgan AS, Kinky DE, Weiner M, Gibson GA, Fishman NO (2001). Impact of a hospital based antimicrobial management program on clinical and economic outcomes. Clinical Infectious Diseases 33:289295 .

Guardabassi L, Prescott JF (2015). Antimicrobial stewardship in small animal veterinary practice: from theory to practice. Veterinary Clinics of North America: Small Animal Practice 45:361-376

Haque M, Rahman NIA, Zulkifli Z, Ismail S (2016). Antibiotic prescribing and resistance: knowledge level of medical students of clinical years of University Sultan Zainal Abidin, Malaysia. Therapeutics and Clinical Risk Management 12:413-426.

Harakeh S, Almatrafi M, Ungapen H,Hammad R, Olayan F, Hakim R, Ayoub M,... Cals JW (2015). Perceptions of medical students towards antibiotic prescribing for upper respiratory tract infections in Saudi Arabia. BMJOpen Respiratory Research 23: e000078.

Hoque R, Mostafa A, Haque M (2016). Insight of medical students of clinical years to antimicrobials prescribing and resistance in private medical school, Chittagong Bangladesh. Journal of Young Pharmacists $8(4): 447-455$.

Johnson TP, Wislar JS (2012). Response rates and nonresponse errors in surveys. JAMA 307:1805-1806

Justo IN, Gauthier TP, Scheetz MH, Chahine EB, Bookstaver PB, Gallagher JC, ... MacDougall C (2014). Knowledge and attitudes of Doctor of Pharmacy students regarding the appropriate use of antimicrobials. Clinical Infectious Diseases 59(Suppl 3):S162-S169.

Keessen EC, Gaastra W, Lipman LJ (2011). Clostridium difficile infection in humans and animals, differences and similarities. Veterinary Microbiology 153:205-217.

Khan MU, Hassali MAA, Ahmad A, Elkalmi RM, Zaidi STR, Dhingra S (2016). Perceptions and practices of community pharmacists towards antimicrobial stewardhip in the state of Selangor, Malaysia. PLOS ONE 11:e0149623.

Khan Y, Boschmans S-A, McCartney J (2017). Undergraduate antimicrobial stewardship training for pharmacy students: creating a foundation for containment of antimicrobial resistance in South Africa. South African Medical Journal 107(9):722

Lanza VF, Baquero F, Martinez L, Ramos-Ruíz R, González-Zom B, Andremont A, ... Coque TM (2018). In-depth resistome analysis by targeted metagenomics. Microbiome 6:11.

Lee C-R, Lee JH, Kang L-W, Jeong BC, Lee SH (2015). Educational 
effectiveness, target, and content for prudent antibiotic use. Biomed Research International http://dx.doiorg/10.1155/2015/214021

Llor C, Bjernum L (2014). Antimicrobial resistance: risk associated with antibiotic overuse and initiatives to reduce the problem. Therapeutic Advances in Drug Safety 5(6):229-241.

Luther VP, Ohl CA, Hicks LA (2013). Antimicrobial stewardship education for medical students. Clinical Infectious Diseases 57(9):1366.

MacDougall C, Schwartz BS, Kim L, Nanamori M, Shekarchian S, ChinHong PV (2017). An interprofessional curriculum on antimicrobial stewardship improves knowledge and attitudes toward appropriate antimicrobial use and collaboration. Open Forum Infectious Diseases 4:ofw225.

MacDougall C, Polk RE (2005). Antimicrobial stewardship programs in health care systems. Clinical Microbiology Reviews 18:638-656.

Maurer FP, Christner M, Hentschke M, Rhode H (2017). Advances in rapid identification and susceptibility testing of bacteria in clinical Microbiology laboratory: implications for patient outcome and antimicrobial stewardship program. Infectious Disease Reports 9:6839.

Minen MT, Duquaine D, Marx MA, Weiss D (2010). A survey of knowledge, attitudes, and beliefs of medical students concerning antimicrobial use and resistance. Microbial Drug Resistance 16(4):285289.

Moran D (2017). Antimicrobial resistance in animal agriculture: understanding user attitude and behaviours. Veterinary Record 181(19):508-509.

Nordmann P, Jayol A, Poirel L (2016). Rapid detection of polymyxin resistance in Enterobacteriaceae. Emerging Infectious Diseases 22:10381043.

Nori P, Madaline T, Munjal I, Bhar S, Guo Y, Seo SK, ... Ostrowsky B (2017). Developing interactive antimicrobial stewardship and infection prevention curricula for diverse learners: A tailored approach. Open Forum Infectious Diseases 10.1093/ofid/ofx117.

O'Donnell LA, Guarascio AJ (2017). The intersection of antimicrobial stewardship and microbiology: educating the next generation of health care professionals. Frontiers in Microbiology Letters 364: fnw281

O'Neill J (2014) Antimicrobial resistance: tackling a crisis for the health and wealth of nations. Review on antimicrobial resistance. http://amrreview.org/Publications.

Oberje EJM, Tanke MAC, Jeurissen PPT (2017). Antimicrobial stewardship initiatives throughout Europe: proven value for money. Infectious Disease Reports 9:6800.

Ohl CA, Luther VP (2014). Health care provider education as a tool to enhance antibiotic stewardship practices. Infectious Disease Clinics of North America 28:177-193.

Okeke IN, Peeling RW, Goossens H, Auckenthaler R, Olmsted SS, De Lavison JF, Nordqvist K (2011). Diagnostics as essential tools for containing antibacterial resistance. Drug Resistance Updates 14:95-106.

Padmanabha TS, Nandini T, Manu G, Madhav KS, Ravi SM (2016). Knowledge, attitude and practices of antibiotic usage among the medical undergraduates of a tertiary care teaching hospital: an observational cross-sectional study. International Joumal of Basic and Clinical Pharmacology 5:2432-2436.
Pereira NR, Castro-Sanchez E, Nathwani D (2017). How can multiprofessional education support better stewardship. Infectious Disease Reports 9:6917.

Prestinaci F, Pezzotti P, Pantosti A (2015). Antimicrobial resistance: a global multifaceted phenomenon. Pathogens and Global Health 109(7):309-318.

Pulcini C, Gyssens IC (2013). How to educate prescribers in antimicrobial stewardship practices. Virulence 4:192-202.

Pulcini C, Williams F, Molinari N, Davey P, Nathwani D (2011). Junior doctors' knowledge and perceptions of antibiotic resistance and prescribing a survey in France and Scotand. Clinical Microbiology and Infection 17:80-87.

Roca I, Akova M, Baquero F, Carlet J, Cavaleri M, Coenen S, ... Vila J (2015). The global threat of antimicrobial resistance: science for intervention. New Microbes New Infection 6:22-29.

San Francisco CN, Toro MD, Cobo J, De Ge-Garcia J, Vano-Galvan S, Moreno Ramos F, ... Pano-Parodo JR (2013). Knowledge and perceptions of junior and senior Spanish resident doctors about antibiotic use and resistance: Results of a multicenter survey. Enfermedades Infecciosas y Microbiología Clínica 31:199-204.

Scaioli G, Gualano MR, Gili R, Masucci S, Bert F, Siliquini R (2015). Antibiotic use: a cross-sectional survey assessing the knowledge, attitudes and practices amongst students of a school of medicine in Italy. PLoS ONE 10:e0122476.

Schellack N, Pretorius R, Messina AP (2016). Esprit de corps': Towards collaborative integration of pharmacists and nurses into antimicrobial stewardship programmes in South Africa South African Medical Journal 106(10):974.

Schwartz BS, Armstrong WS, Ohl CA, Luther VP (2015). Create allies, IDSA stewardship commitments should prioritize health professions learners. Clinical Infectious Diseases 61(10):1626-1627.

Schwartz BS, Chin-Hong PV (2017). A call to action: Infectious diseases medical educators needed. Journal of Infectious Diseases 216:600-605.

Schwartz DN (2016). Antimicrobial stewardship in US hospitals: Is the cup half-full yet? Clinical Infectious Diseases 63(4):450-453.

Schwartz S, Loeffler A, Kadle K (2016). Bacterial resistance to antimicrobial agents and its impact on veterinary and human medicine. Veterinary Dermatology 28(1):82-e19.

SchwartzBS, ArmstrongWS, OhlCA, Luther VP (2017). Create allies, IDSA stewardship commitments should prioritize health professions learners. Clinical Infectious Diseases 61:1626-1627.

Shanuga Vadivoo N, Usha B, Padmavathi BK (2015). Assessment of clinician's knowledge and perception on antimicrobial resistance a primary strategy for antimicrobial resistance control. Global Journal Medical Research 15(4): https :// medical research journal .org /index.php/GJMR/article/view/982

Shrayteh ZM, Rahal MK, Malaeb DN (2014). Practice of switch from intravenous to oral antibiotics. Springer Plus 3:717.

Speksnijder DC, Jaarsma ADC, Van Der Gugten AC, Verheij TJ, Wagenaar JA (2015). Determinants associated with veterinary antimicrobial prescribing in farm animals in the Netherlands: a qualitative study. Zoonoses and Public Health 62:39-51. 
174

Spellberg B, Guidos R, Gillbert D, Bradley J, Boucher HW, Scheld WM, .. Infectious Diseases Society of America (2008). The epidemic of antibiotic resistant infections: a call to action for the medical community from the Infectious Diseases Society of America. Clinical and Infectious Diseases 46(2):155-164

Spohr A, Schjoth B, Wiinberg B, Houser G, Willersen J, Jessen LB, Guardabassi L, ... Jessen VE (2012) Antibiotic use guidelines for companion animal practice.

Steiner E, Saddler LC, Fagnan LJ (2004). Promoting appropriate antibiotic use: Teaching doctors, teaching patients. Californian Journal of Health Promotion 2:2-30.

Tarao MS, Nulla P, Zingpi M, Agatha G (2015). A study on the knowledge, attitude, perceptions and practices of antibiotic usage and resistance among the medical students of Jnims, Imphal, Manipur. Journal of Evidenced Based Medicine and Healthcare 2:5262-5268.

Theuretzbacher U, Ardal C, Harbarth S (2017). Linking sustainable usc policies to novel economic incentives to stimulate antibiotic research anc development. Infectious Disease Perspectives 9:6836.

Thriemer K, Katuala Y, Batoko B, Alworonga JP, Devier H, Vangeet C, .. Jacobs J (2013). Antibiotic prescribing in DR Congo: A knowledge, attitude and practice survey among medical doctors and students. PLos ONE 8, doi:10.1371/journal.pone.0055495.

Van Boeckel TP, Brower C, GilberT M, Grenfell BT, Levin SA, Robinson TP, Teillant A, Laxminarayan R (2015). Global trends in antimicrobial use in food animals. Proceedings of National Academy of Sciences USA 112(18):5649-5654.

Vickers H (2011). International antibiotic resistance crisis. Better trainin̨̧ needed to maintain therapeutic arsenal. Student BMJ 19:d3207.

Wasserman S, Potgieter S, Shoul E, Constant D, Stewart A., Mendelson M, Boyles TH (2017). South African medical students' perceptions anc knowledge about antibiotic resistance and appropriate prescribing Are we providing adequate training to future prescribers? South African Medical Journal 107(5):405-410.

Weese JS, Giguère S, Guardabassi L, Morley PS, Papich M, Ricciuto DR, Sykes JE (2015). ACVIM consensus statement on therapeutic antimicrobial use in animals and antimicrobial resistance. Journal of Veterinary Internal Medicine 29(2):487-498.
Weier N, Thursky K, Zaidi STR (2017). Antimicrobial knowledge and confidence amongst final year medical students in Australia. PLOS ONE 12:e0182460.

Wesse JS, Blondeau JM, Boothe D, Brietschwerdt EB, Guardabassi L, Hillier A (2011). Antimicrobial use guidelines for treatment of urinary tract diseases in dogs and cats. Antimicrobial Guidelines Working Group for companion animals infectious diseases. Veterinary Medicine International doi:10.4061/201 1/263768.

Wickens HJ, Farrell S, Ashiru-Oredope DAI, Jacklin A, Holmes A (2013). The increasing role of pharmacists in antimicrobial stewardship in English hospitals. In: Collaboration with the Antimicrobial Stewardship Group of the Department of Health Advisory Committee on Antimicrobial Resistance and Health care Associated Infections (ASG ARHAI). Jounal of Antimicrobial Chemotherapy 68:2675-2681.

World Health Organization (WHO) (2011). WHO list of critically important antimicrobials (CIA), 3rd revision.

World Health Organization (WHO) (2012). The evolving threat of antimicrobial resistance. Options for action. Geneva: World Health Organization.

World Health Organization (WHO) (2016). List of critically-important antimicrobials for human use, 5 th revision.

World Health Organization (WHO) (2017). Global priority list of antibiotic-resistant bacteria to guide research, discovery and development of new antibiotics.

Yang K, Wu D, Tan F, Shi S, Guo X, Min Q, Zhang X, Cheng H (2016). Attitudes and perceptions regarding antimicrobial use and resistance among medical students in Central China. Springerplus 5(1):1779.

Zaidi AK, Awasthi S, Desilva HJ (2004). Burden of infectious diseases in South Asia. BMJ 328(7443):811-815. 